\title{
PHOTOGRAPHIC RESULTS OF THE LUNAR ORBITER PROGRAM
}

\author{
William E. BRUNK \\ (NASA, Washington, D.C., U.S.A.)
}

The principal goal of the Lunar Orbiter program was to obtain photographic coverage of selected areas of the lunar surface at resolutions of 1 and $8 \mathrm{~m}$. As the success of the program was greater than originally anticipated, the photographic coverage was extended to include the entire front side of the Moon at a resolution one order of magnitude greater than possible from the Earth and almost all of the far side. In this paper, a selection of photographs obtained from all five missions will be presented. These photographs show many interesting and previously unobserved features. However, no attempt will be made herein to analyze or interpret such features.

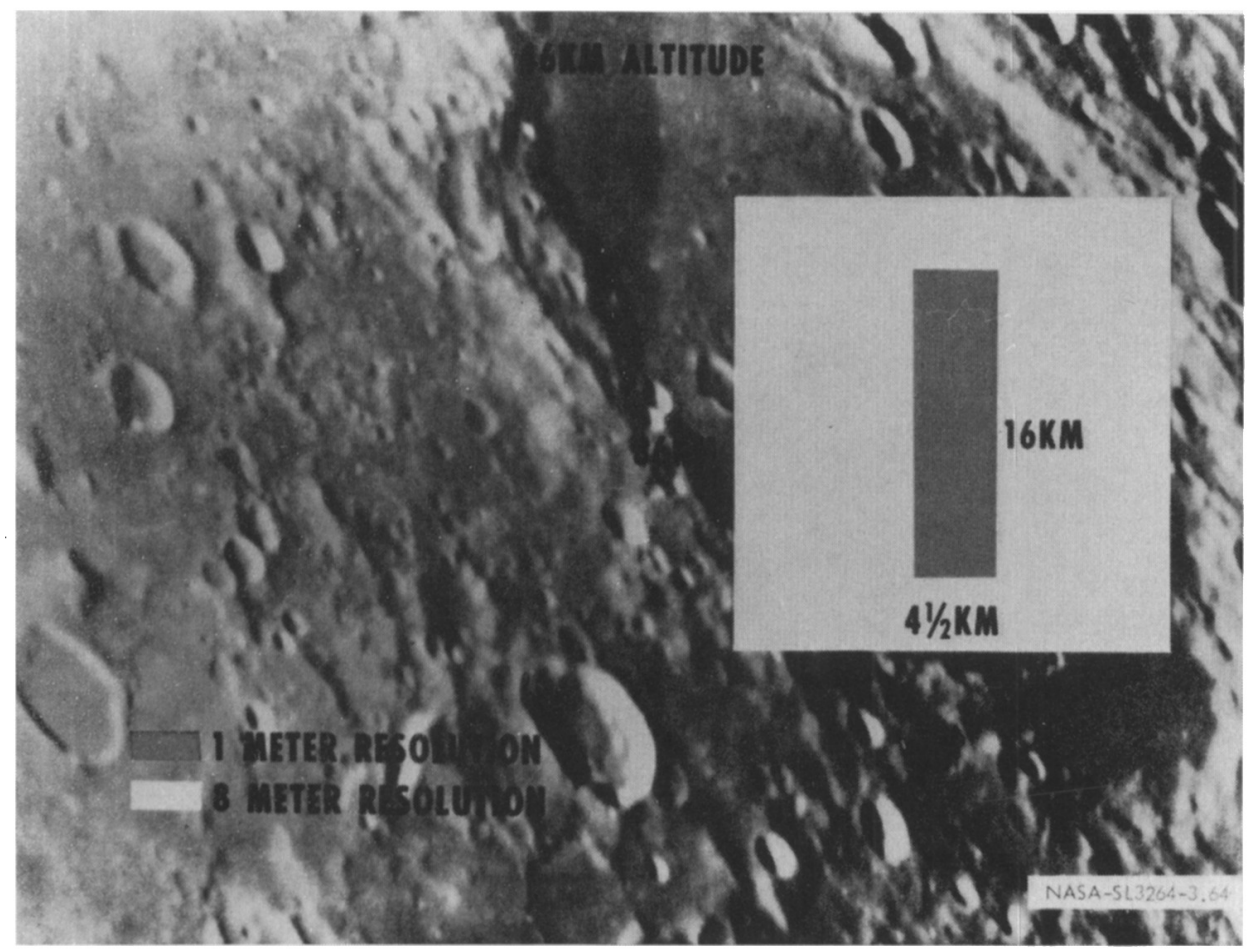

FIG. 1.

Perek (ed.), Highlights of Astronomy, 471-523. () I.A.U. 
Analysis and interpretation is being carried out by a number of scientists and will be reported in the journals.

The relative coverage obtained with the two Lunar Orbiter cameras is shown in Figure 1 for a spacecraft altitude of $46 \mathrm{~km}$ and with the optical axis of the cameras normal to the lunar surface. The 24-inch focal-length lens produced a high-resolution photograph with $1-\mathrm{m}$ resolution over an area of 4.5 by $16 \mathrm{~km}$ as indicated by the dark gray color, while the 3 -inch lens produced a moderate-resolution photograph with 8 -m resolution over the lighter gray area of 32 by $37 \mathrm{~km}$. Both a high- and moderateresolution photograph are obtained with each exposure. Portions of the high- and moderate-resolution photographs of a region in the Sea of Tranquility are shown in Figure 2. The photographs are scaled to give the same linear resolution.

The primary sites that were to be photographed during the Lunar Orbiter-I mission are shown in Figure 3. The sites, indicated by the black dashes, were possible Apollo landing sites as determined from Earth-based photography. The rectangle represents the zone of possible Apollo landing sites. A moderate-resolution photograph of a secondary site is shown in Figure 4. The surface, at a resolution of $8 \mathrm{~m}$, appears to be completely pockmarked with craters. The orbit of Lunar Orbiter-I was elliptical with a perilune altitude of $200 \mathrm{~km}$ and apolune altitude of $1850 \mathrm{~km}$. The high-resolution photography of the frontside, taken near perilune, was blurred due to a malfunction in the altitude-velocity corrector in the camera system. However, excellent high- and moderate-resolution photographs of the lunar far side were obtained. The resolution was considerably less than on the front side as they were taken when the spacecraft was near apolune. A moderate-resolution photograph of an 1100 by $1300 \mathrm{~km}$ region in the western portion of the far side is shown in Figure 5. A similar sized area in the eastern portion of the far side is shown in Figure 6. The dark-floored crater near the bottom is Tsiolkovsky, first detected on the U.S.S.R. Luna-III photography. Many interesting features were noticed on the high-resolution photography of the far side. In Figure 7 is shown a double crater where material from the larger, approximately $52-\mathrm{km}$ diameter, crater has flowed over into the smaller crater. Shown in Figure 8 is $25-\mathrm{km}$ diameter crater with a highly fractured floor. The fractures appear as an irregular pattern like that observed in a dried mud flat. Many examples of craters with fractured floors were seen in later high-resolution photographs on both the near and far sides of the Moon.

The first photographs of the Earth from the vicinity of the Moon were taken on this mission. Figure 9 shows a portion of a high-resolution photograph which shows the Earth just beyond the Eastern limb of the Moon. At the time of the exposure, the American continent was on the limb and Europe was located close to the terminator.

The primary goal of the Lunar Orbiter-II mission was further photography of possible Apollo sites. Representative samples of high-resolution photography of these sites are shown in Figure 10. Although all of the primary sites looked smooth on Earthbased photography, many appeared filled with craters when examined in detail. The 


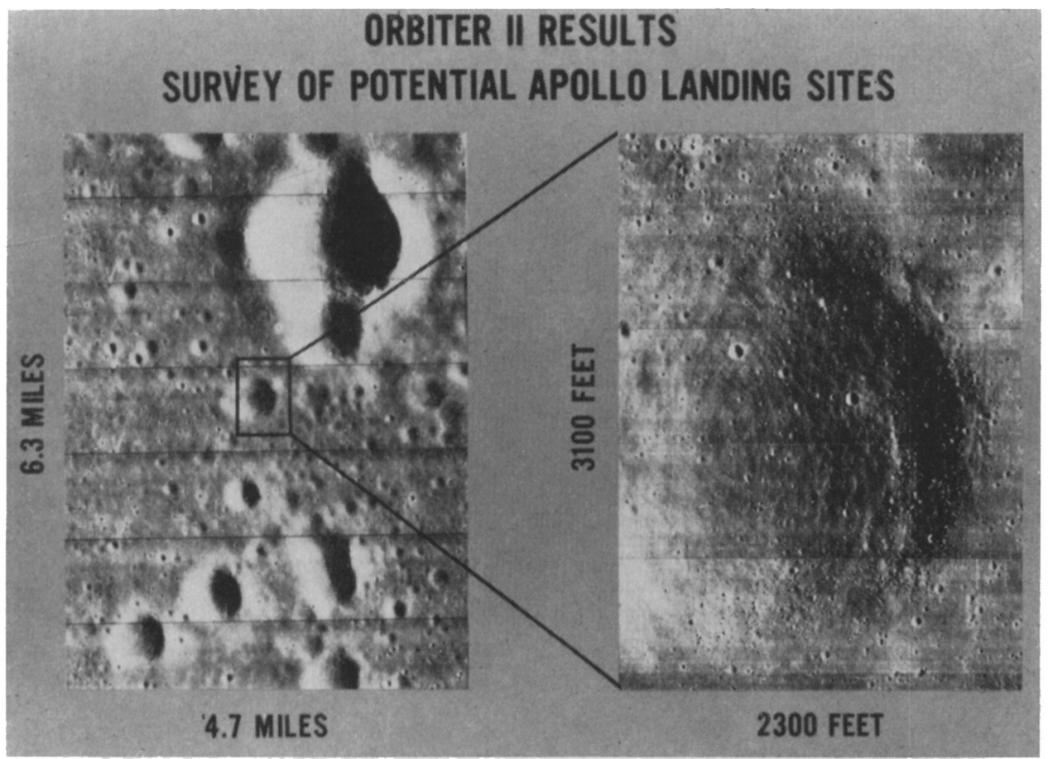

FIg. 2.

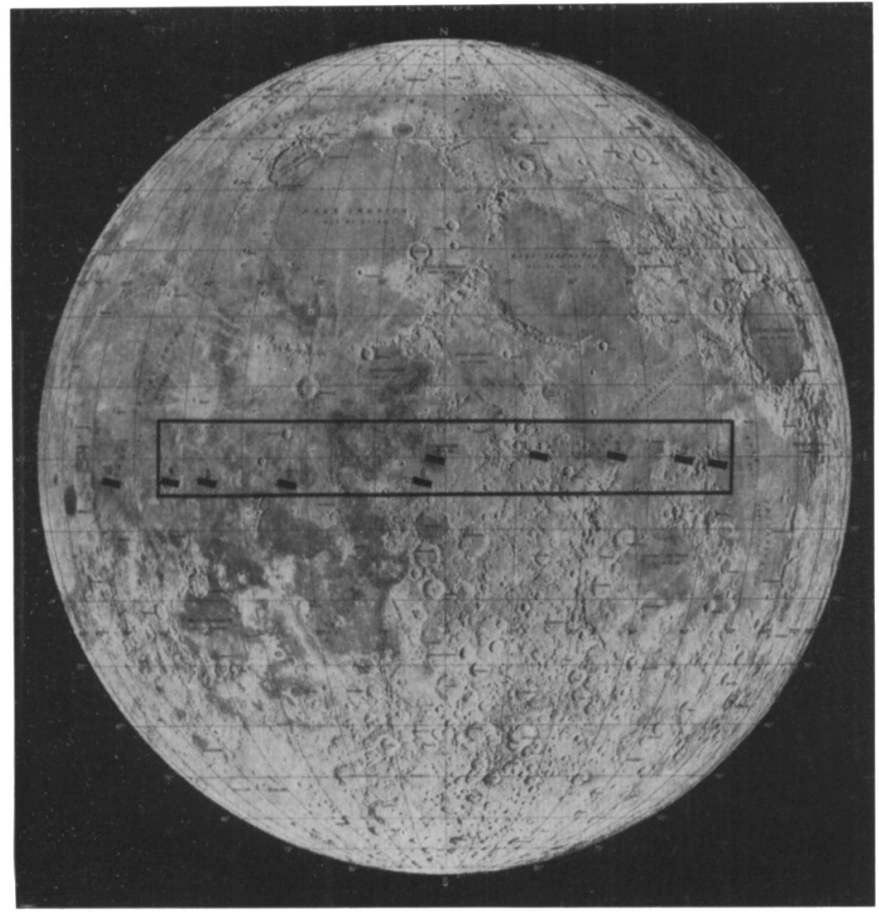

FIG. 3. 


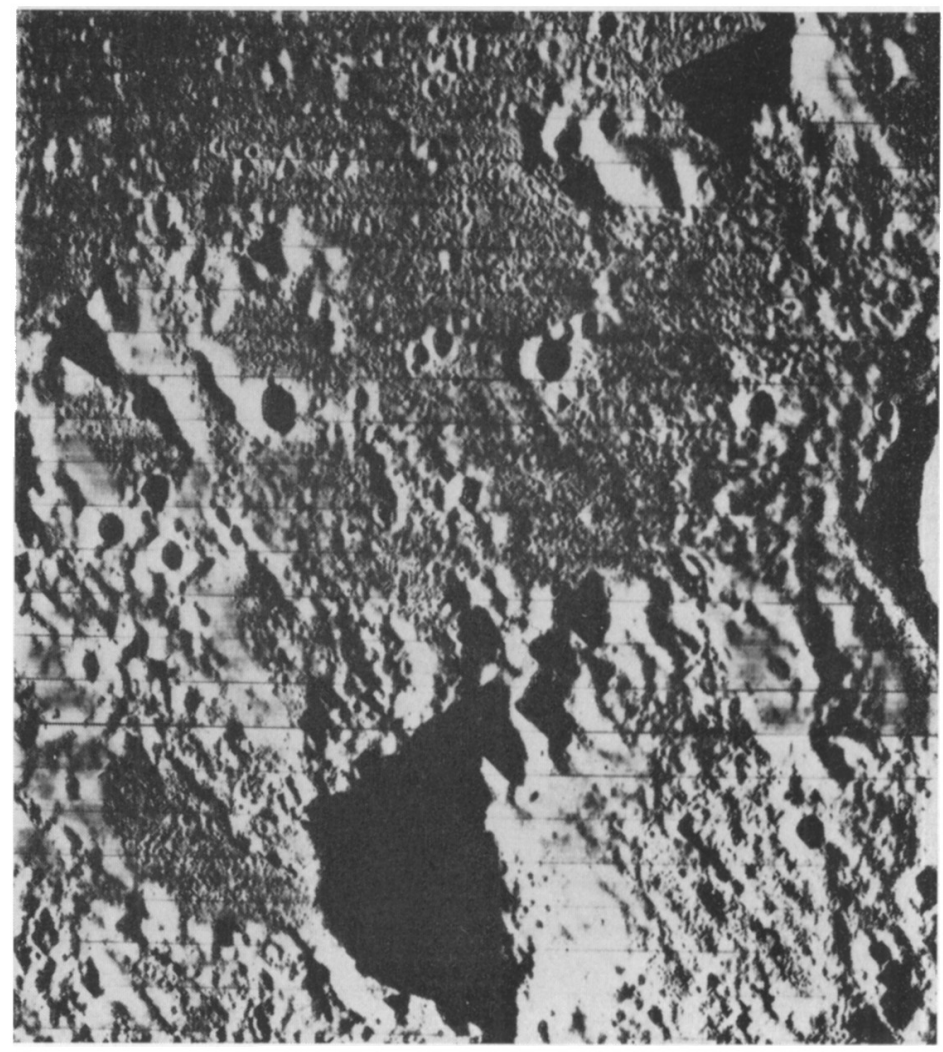

FIG. 4. 


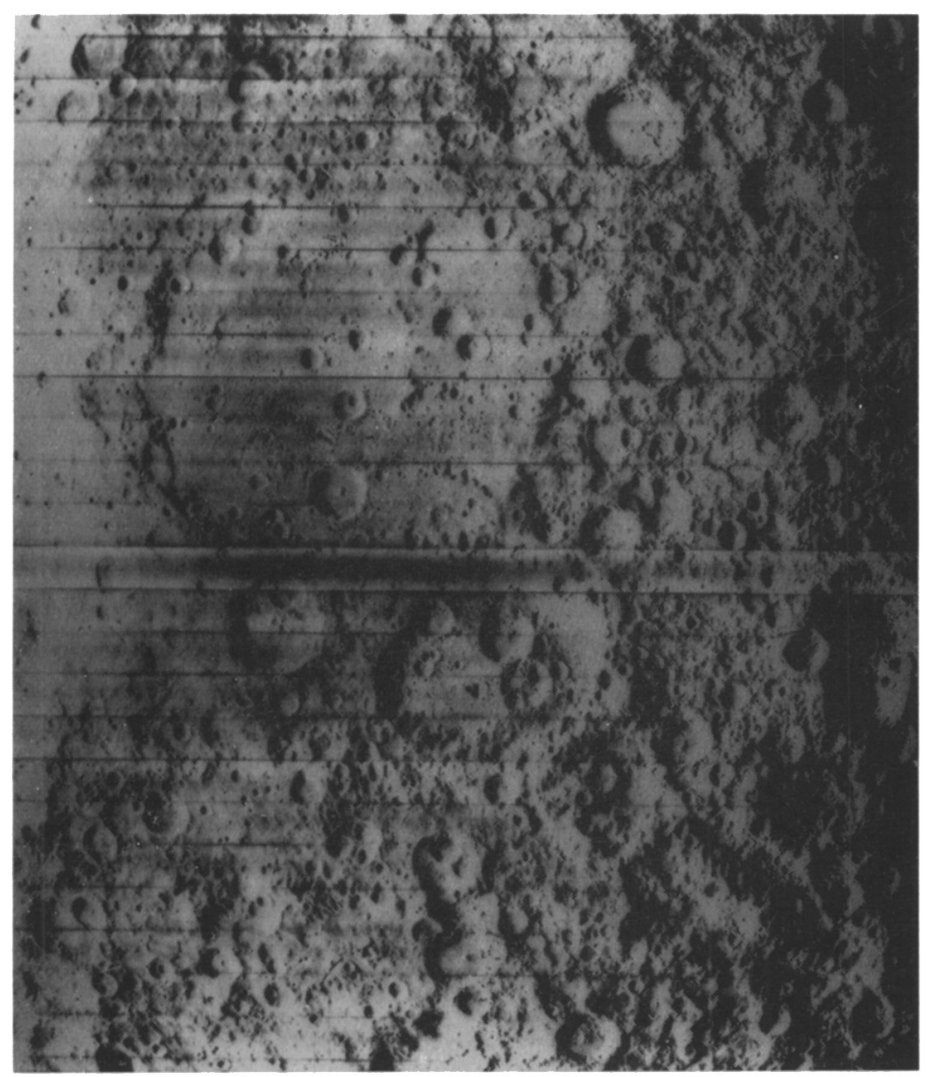

FIG. 5 . 


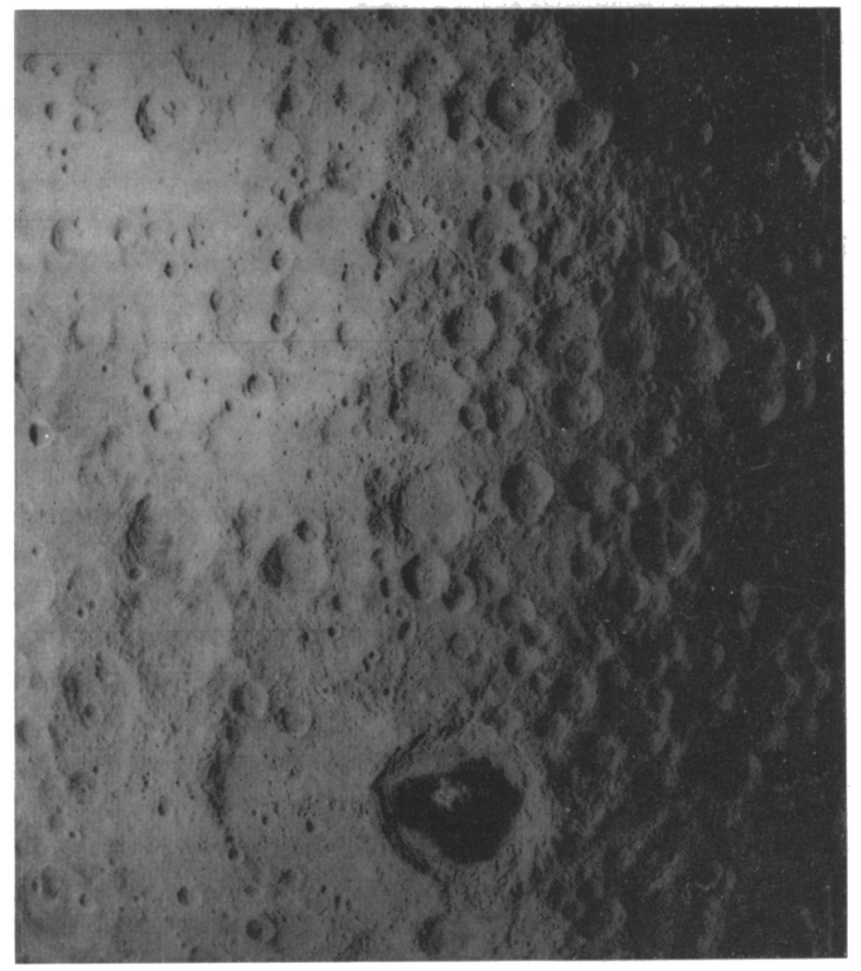

FIG. 6 . 


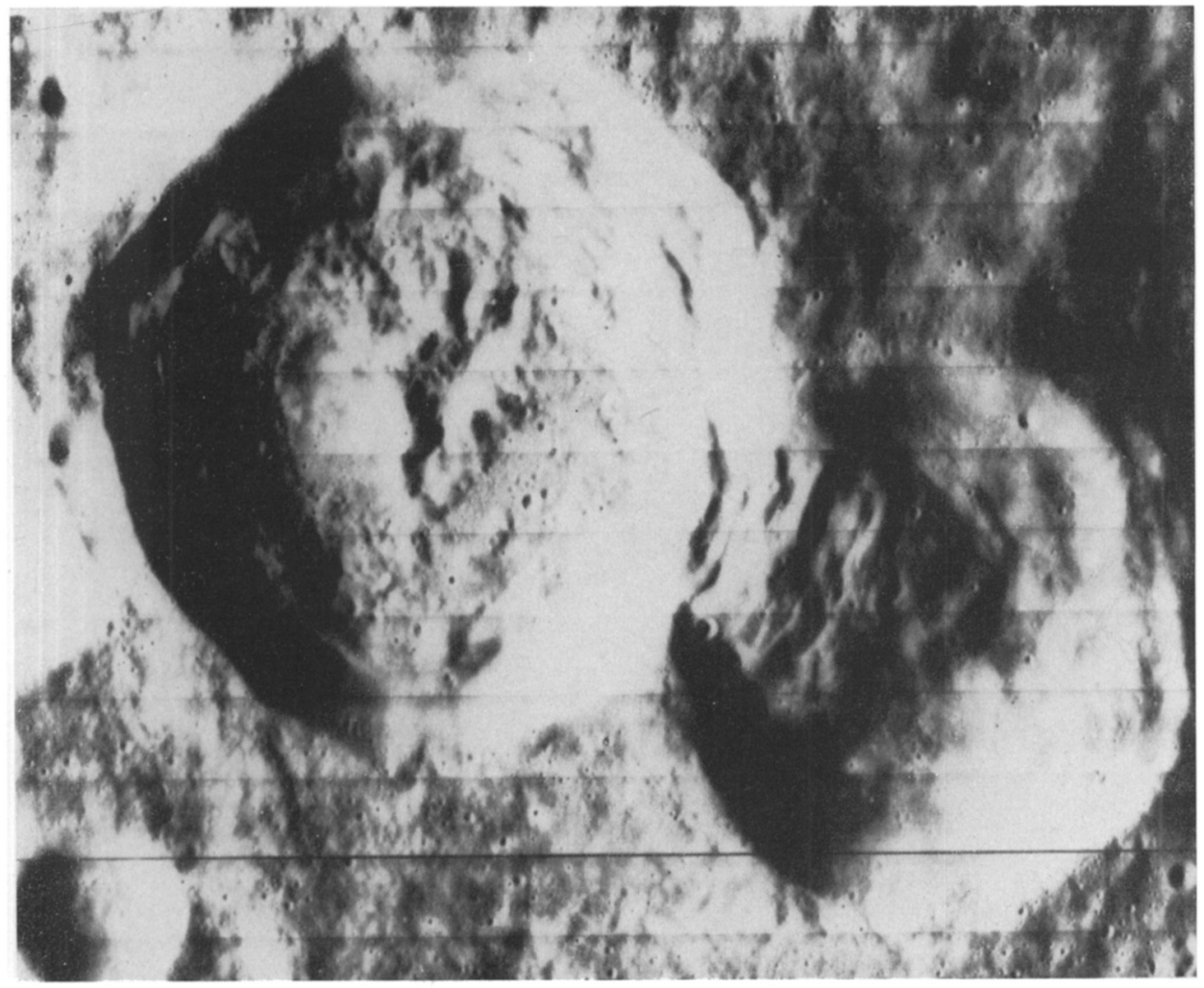

FIG. 7. 


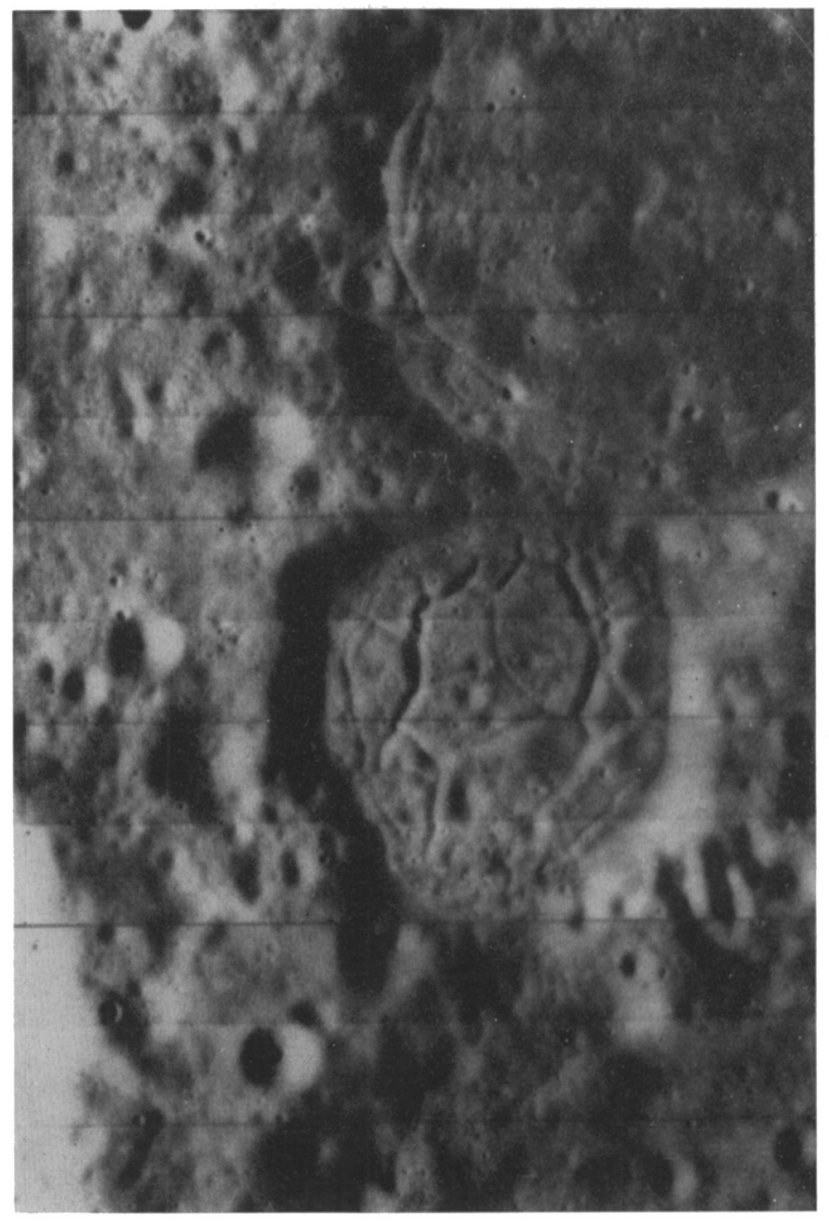

FIG. 8. 


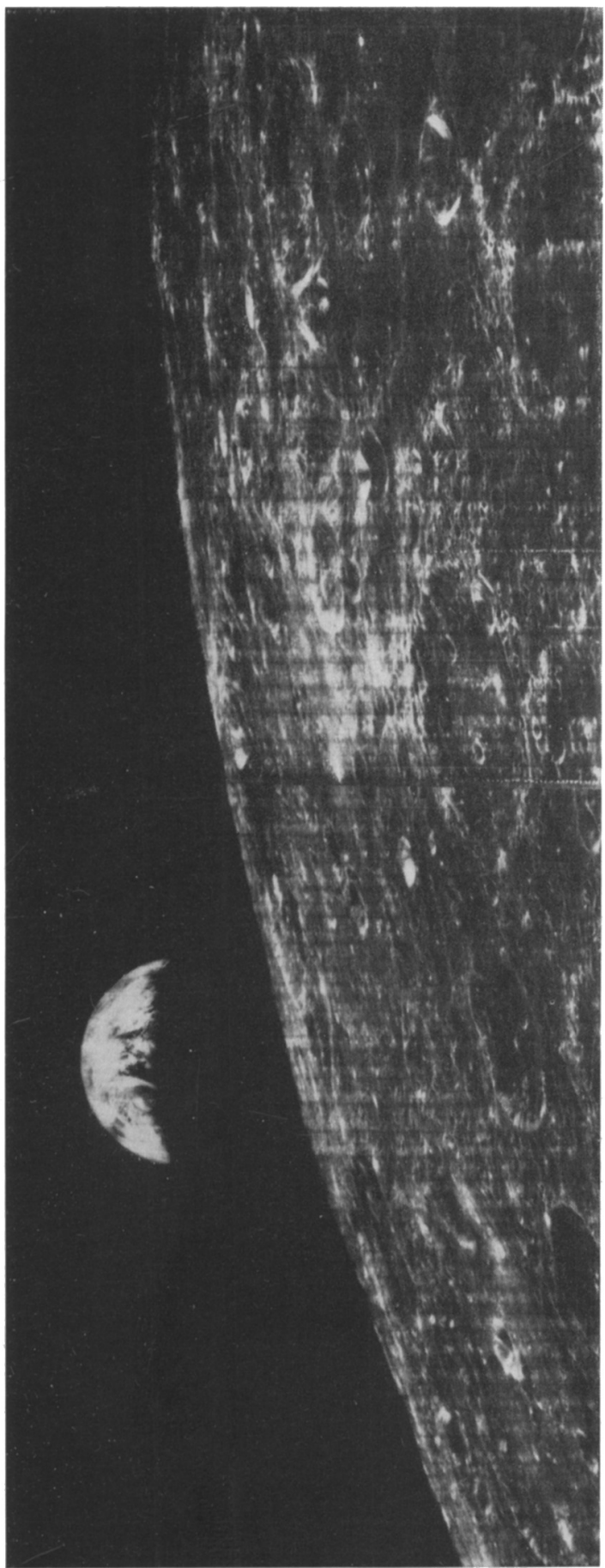

$\stackrel{\dot{9}}{\dot{\varphi}}$ 
resolution in these pictures is approximately $1 \mathrm{~m}$. Interesting features were found in many of the photographs. A rock-strewn area in the southeastern part of Mare Tranquillitatis is shown in Figure 11. The area covered by the photograph is approximately 400 by $500 \mathrm{~m}$. The rock formations are part of a linear feature appearing as a lighter colored ray on the mare surface. A portion of another high-resolution photograph is shown in Figure 12. The large crater is approximately $180 \mathrm{~m}$ across and the area is in the western part of Mare Tranquillitatis.

With the exception of the Earth-Moon picture, all photographs shown thus far were taken with the camera's optical axis nearly normal to the lunar surface. Starting with the Lunar Orbiter-II mission, oblique photography was undertaken. The first oblique photograph was that of the crater Copernicus. An Earth-based photograph of the Copernicus region to illustrate the geometry of the situation is shown in Figure 13. The spacecraft was traveling from right to left along the dashed line and the photograph was taken when the spacecraft was at the point indicated by the $\times$. The fields of view of the moderate- and high-resolution photographs are indicated by the solid white lines. The moderate-resolution photograph is shown in Figure 14. Copernicus is seen near the limb with the double crater Fauth just below it. A section of the high-resolution photograph is seen in Figure 15 with the southern rim of Copernicus in the foreground and the northern rim in the background. The features seen on the floor of the crater are $300-\mathrm{m}$ high mountains. Oblique photography was subsequently used to study other features of interest. A portion of the

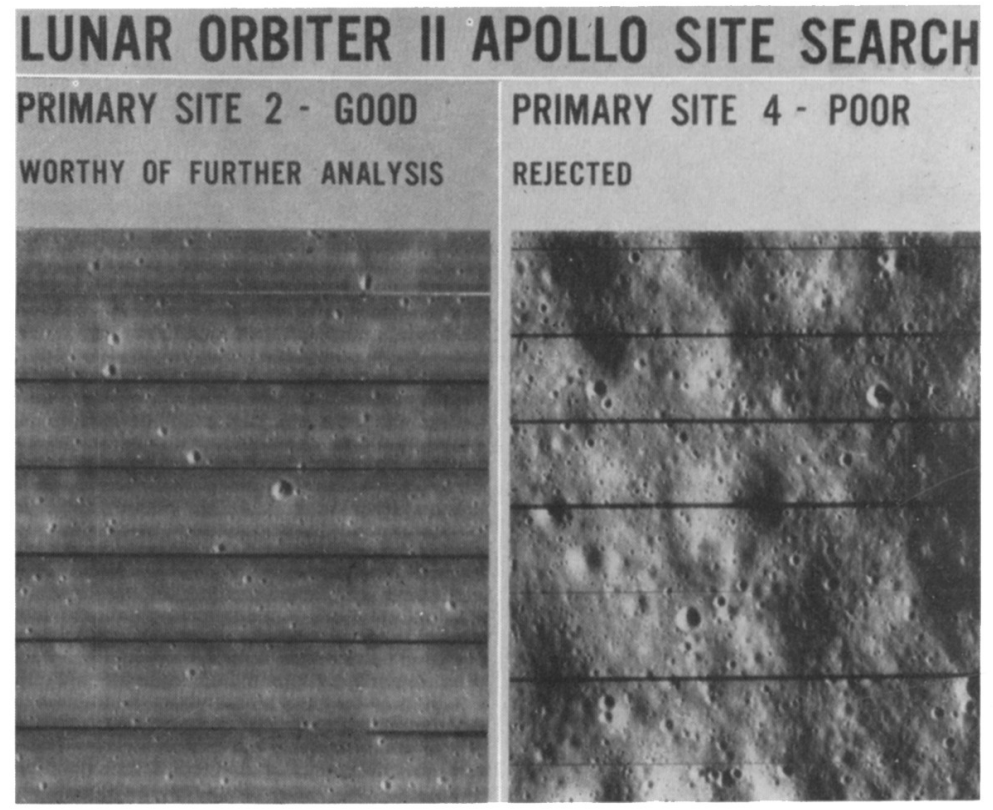

FIG. 10. 


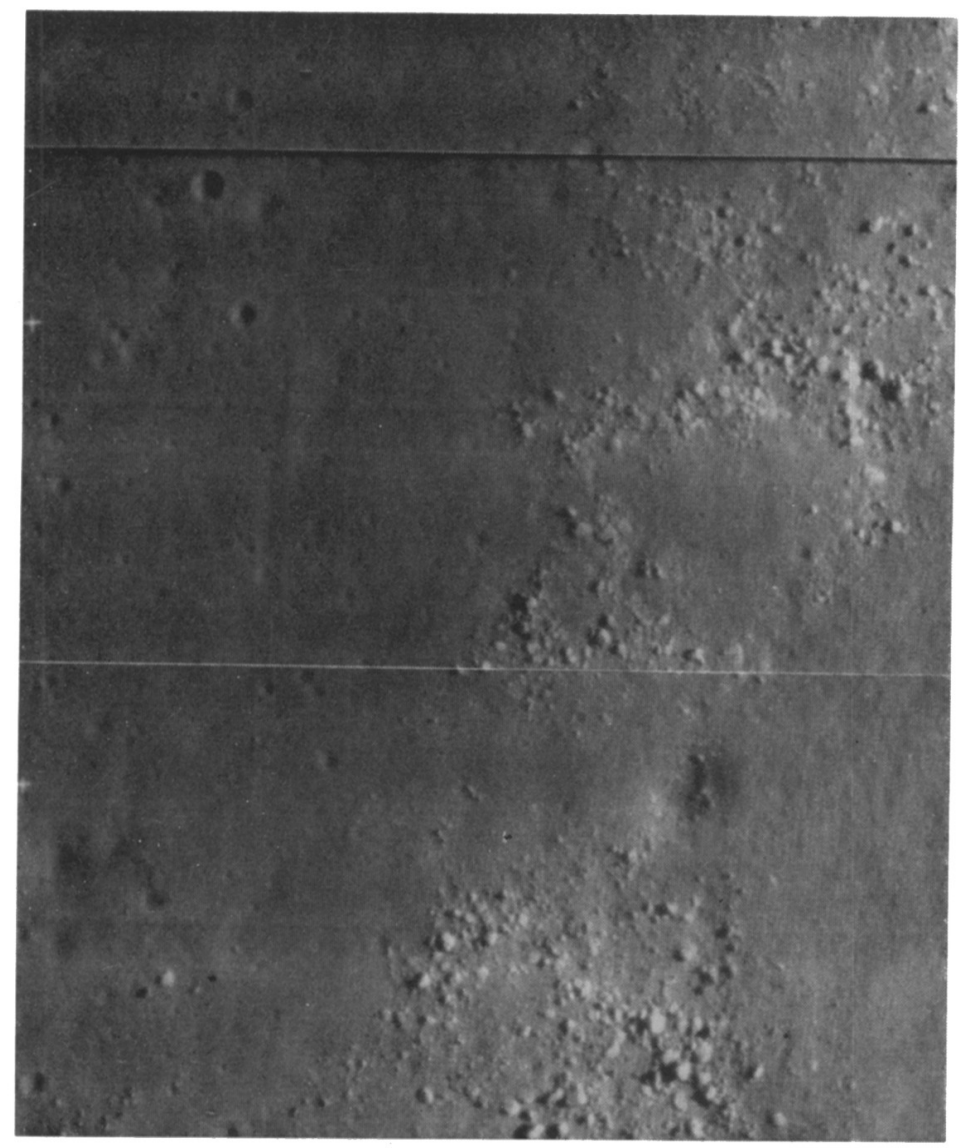

FIG. 11 . 

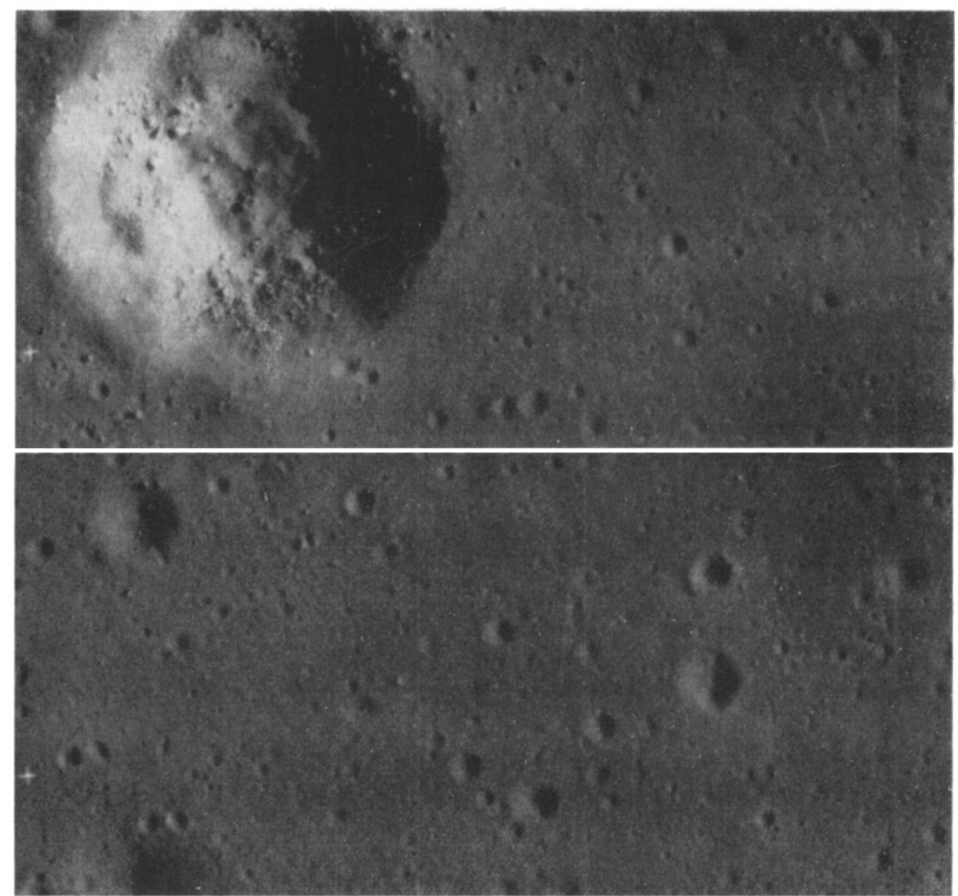

FIG, 12. 


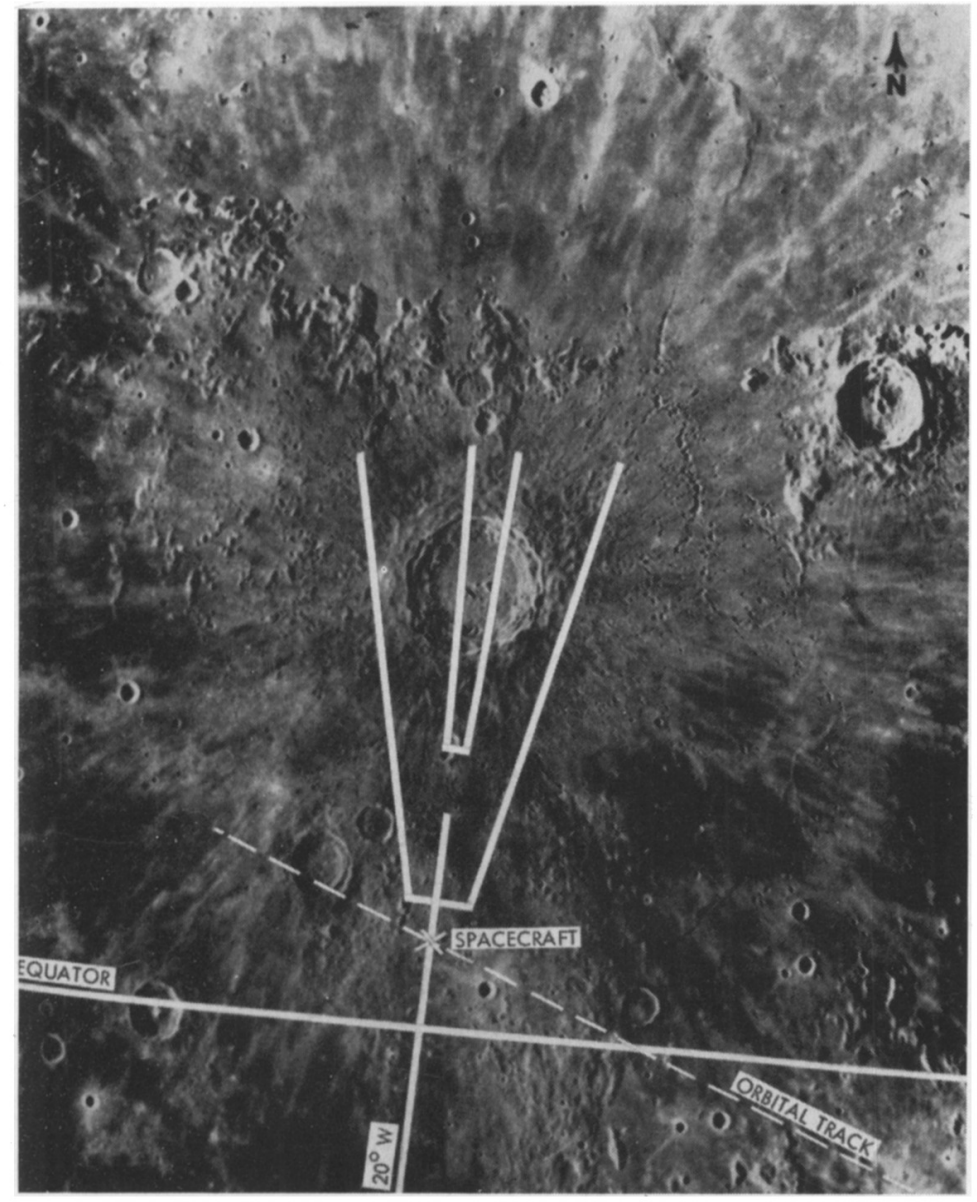

Fig. 13. 


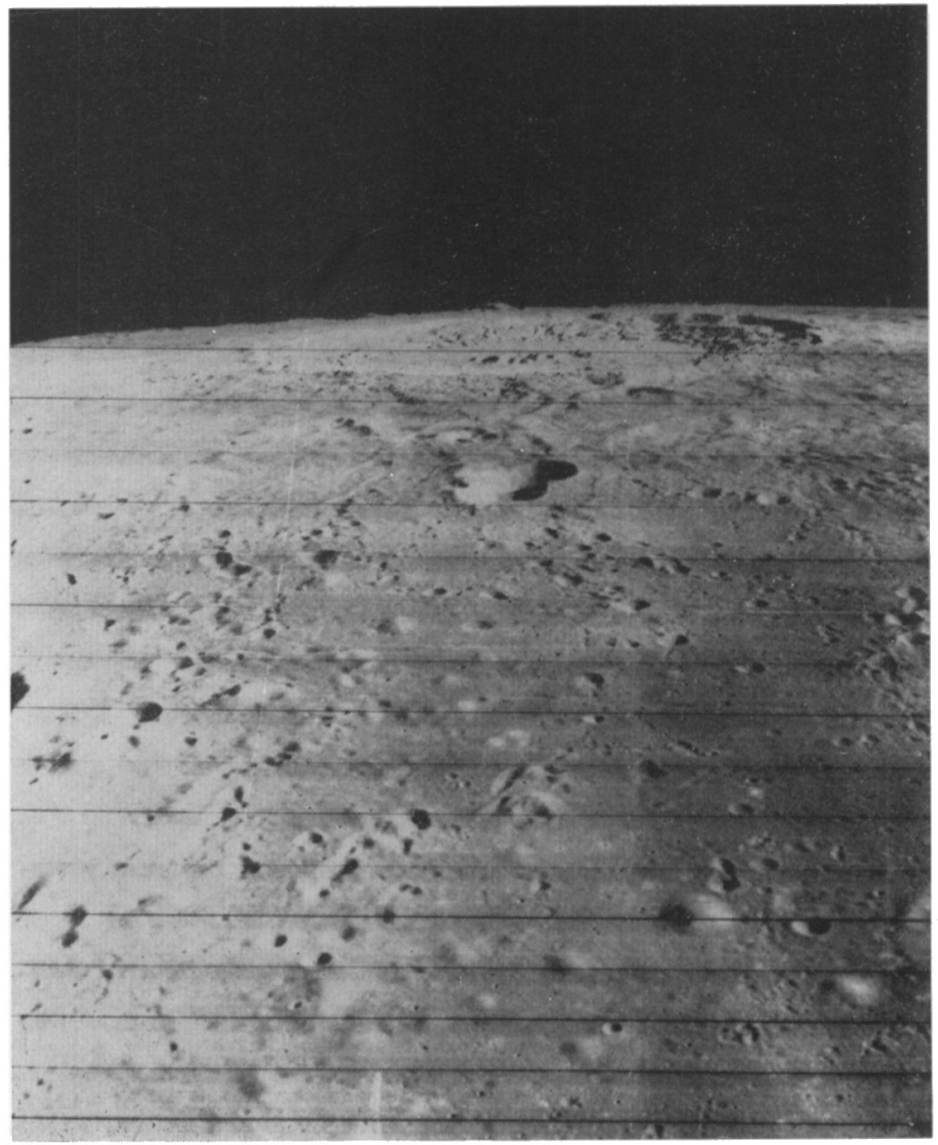

FIG. 14. 
PHOTOGRAPHIC RESULTS OF THE LUNAR ORBITER PROGRAM

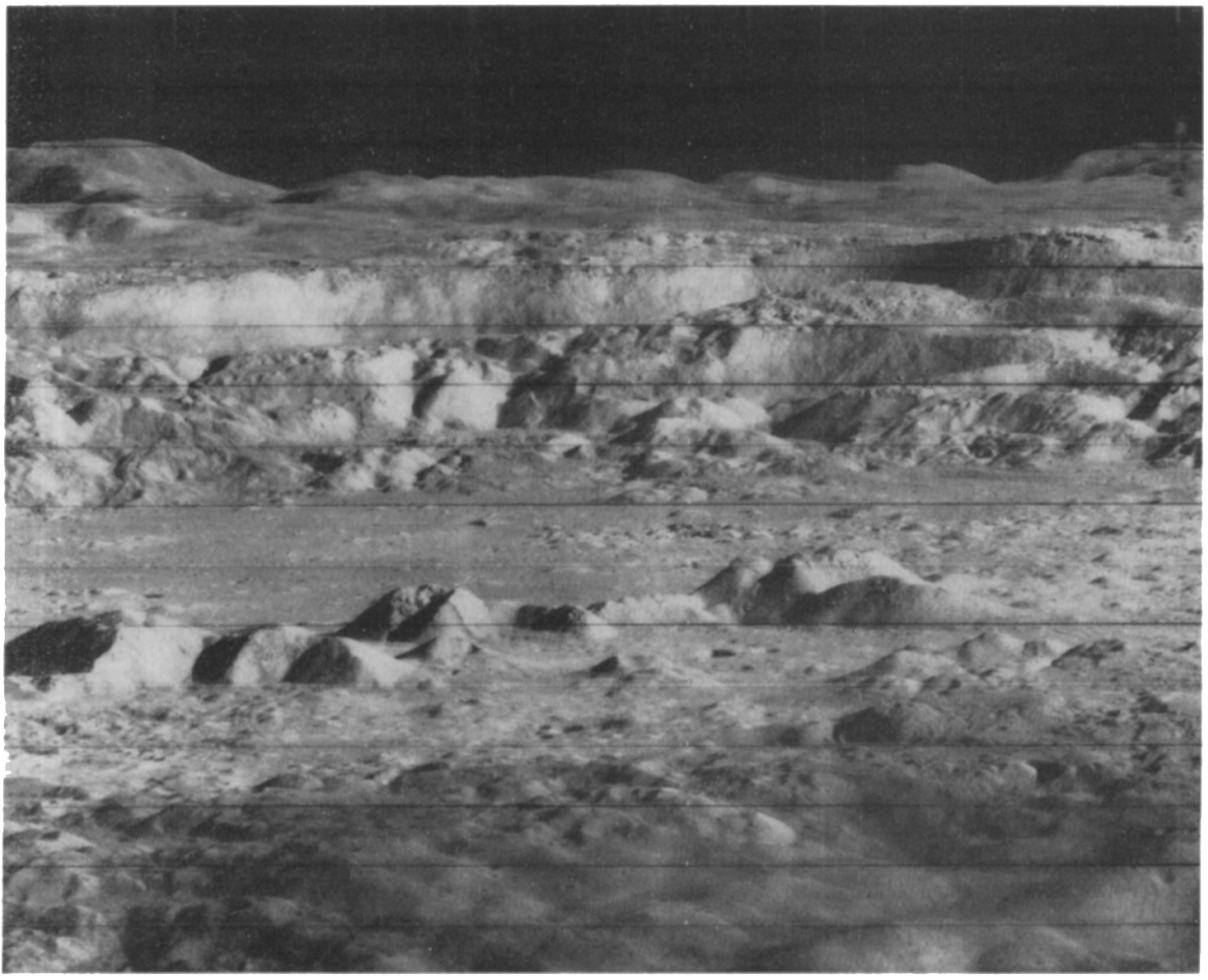

FIG. 15. 
moderate-resolution oblique photograph of the region of the Marius Hills is shown in Figure 16. The crater Marius is seen near the limb slightly to the right of the center. A portion of Oceanus Procellarium near the crater Reiner Gamma is shown in Figure 17. Light-colored ray material can be seen just above center.

The coverage of the lunar far side was extended during the Orbiter-II mission. Oblique photographs were taken looking both north, as seen in Figure 18, and south. Figure 19 is a moderate-resolution vertical photograph of a region of the far side near the eastern limb and centered approximately on the equator. The mare region in the upper left-hand corner is Mare Smythii, which can be observed from the Earth.

The orbit of the Lunar Orbiter-III mission differed from that of the two earlier missions by a change in orbital inclination from $12^{\circ}$ to $21^{\circ}$. This change permitted high-resolution photography of additional regions of scientific interest. Several examples of the vertical and oblique photography are shown in Figures 20-31. A moderate-resolution photograph of a prospective Apollo site in southeastern Mare Tranquillitatis is shown in Figure 20. The area covered is approximately 46 by $39 \mathrm{~km}$. A 42 by $50 \mathrm{~km}$ section of the floor of the crater Hevelius on the western edge of Oceanus Procellarum is shown in Figure 21. Several interesting geological formations are shown in fine detail in Figure 22, which covers an area of approximately $23 \mathrm{~km}^{2}$ in Oceanus Procellarum. An area of approximately $1 \mathrm{~km}^{2}$ near Mare Tranquillitatis is shown in Figure 23. Numerous rocks can be seen on the sloping crater wall. The unusual appearing crater seen in Figure 24 is located in Oceanus Procellarum. The double-walled appearance of the $155-\mathrm{m}$ diameter crater is believed due to a continuous landslide around its circumference.

A familiar feature on the lunar surface is shown in Figure 25. This is a moderateresolution oblique photograph of the Hyginus Rille with the 11-km diameter Hyginus crater at the center. An area known as the Schneckenberg Uplands appears in the upper left corner of the picture. Figure 26 is a moderate-resolution photograph of an area in the region of Kepler, with part of Oceanus Procellarum in the foreground. Kepler is the large crater near the center and Kepler A is seen to the right. The $100-\mathrm{km}$ diameter crater Theophilus is seen in Figure 27. A moderate-resolution photograph of the region near the crater Damoiseau is shown in Figure 28. The general area is in southwestern Oceanus Procellarum. Of considerable interest is the sharply defined contact between the mare floor and the upland areas. Damoiseau, seen to the left of center, is $36 \mathrm{~km}$ in diameter and has an interesting concentric ring structure. Figure 29 shows an area near the crater Galilei, the largest crater seen near the limb, in the northern portion of Oceanus Procellarum. The Cavalerius Hills are shown in the foreground. Located in the area included in this photograph is the landing site of the U.S.S.R. Luna-IX soft-landing spacecraft.

Only one frame of the lunar far side was taken during the Lunar Orbiter-III mission. It is shown in Figure 30 and includes a large portion of the southern portion of the far side. The dark floored crater Tsiolkovsky shows prominently in this photo- 


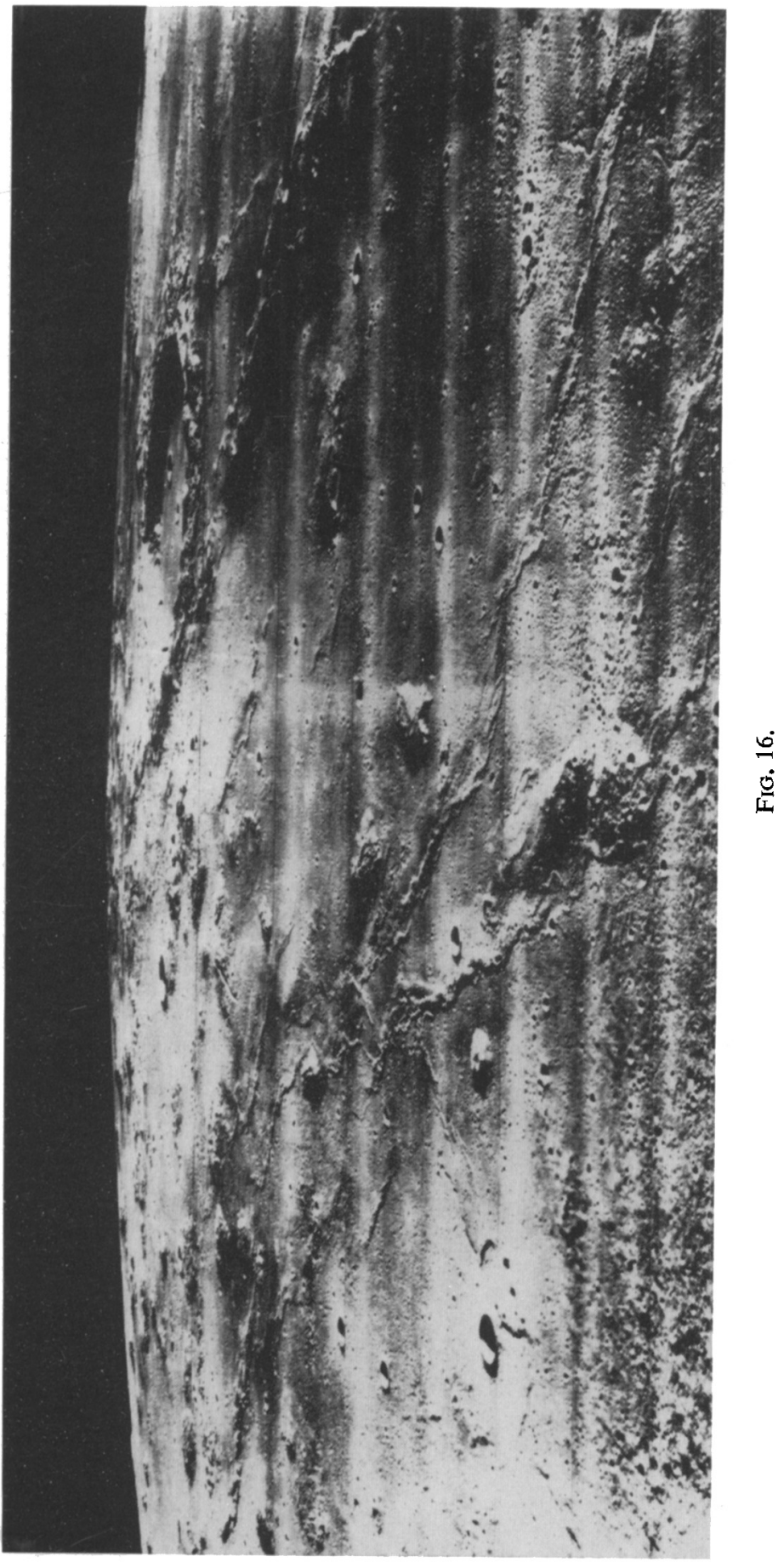




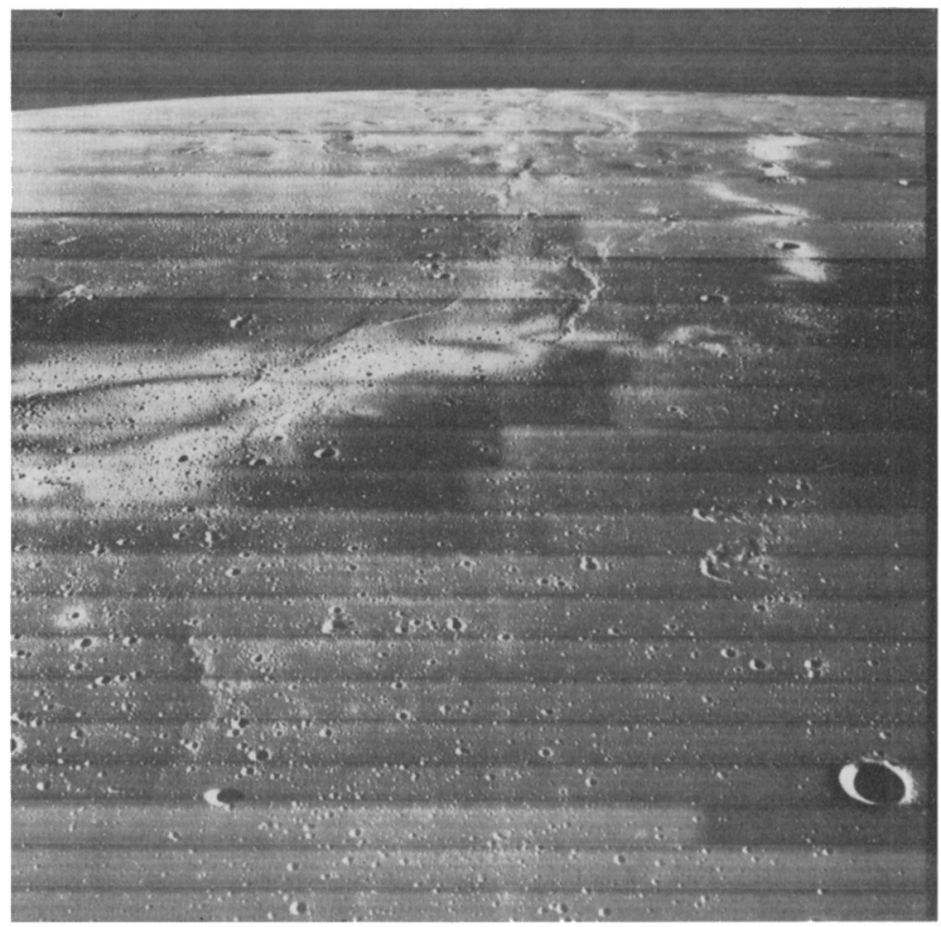

FIG. 17. 
PHOTOGRAPHIC RESULTS OF THE LUNAR ORBITER PROGRAM 489

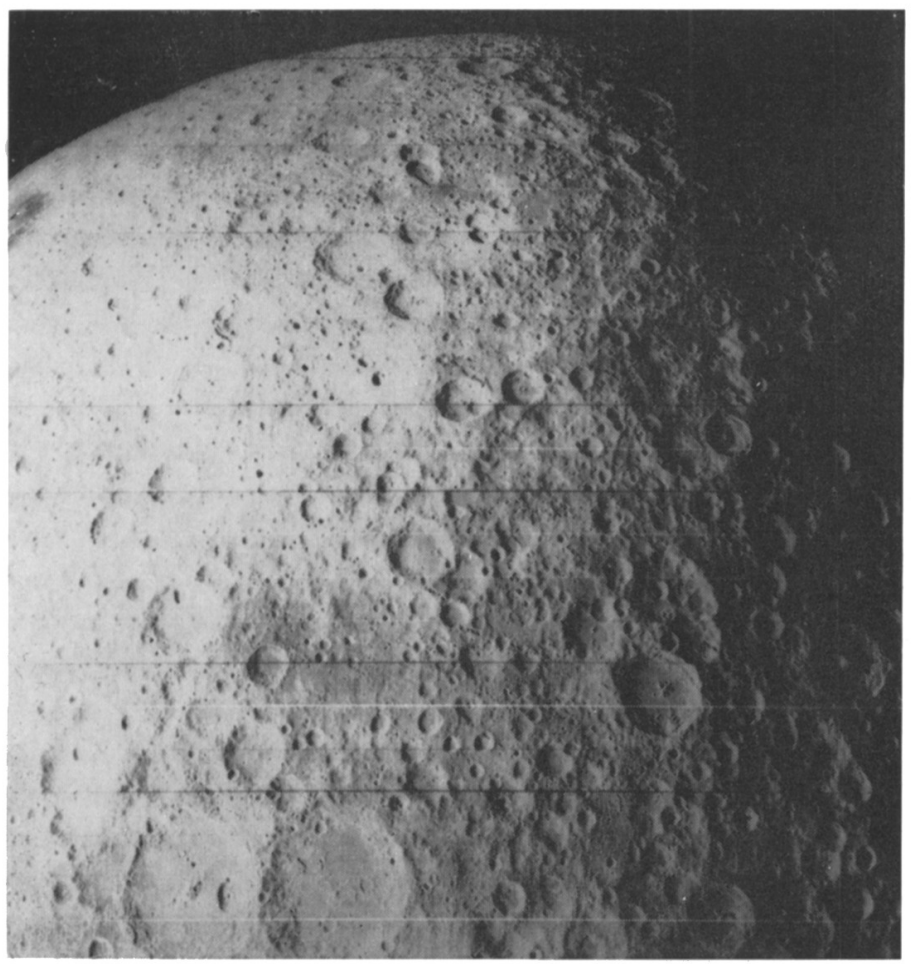

FIG. 18. 


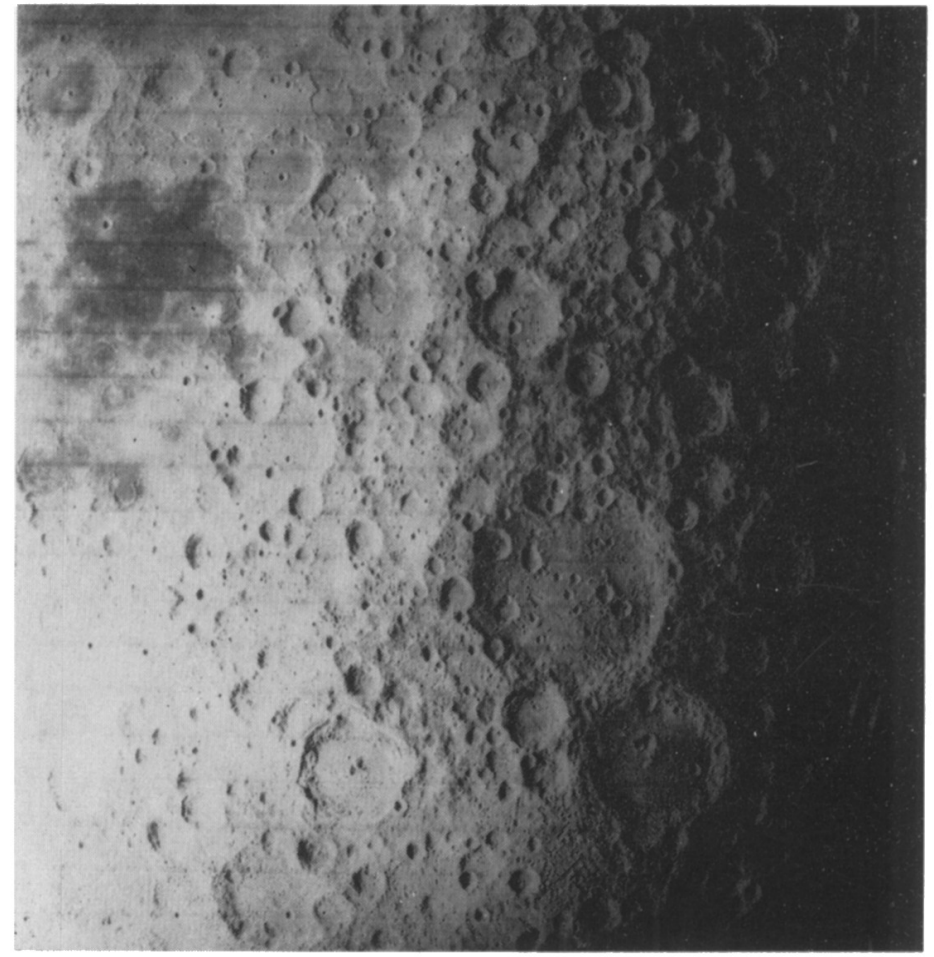

FIG. 19. 


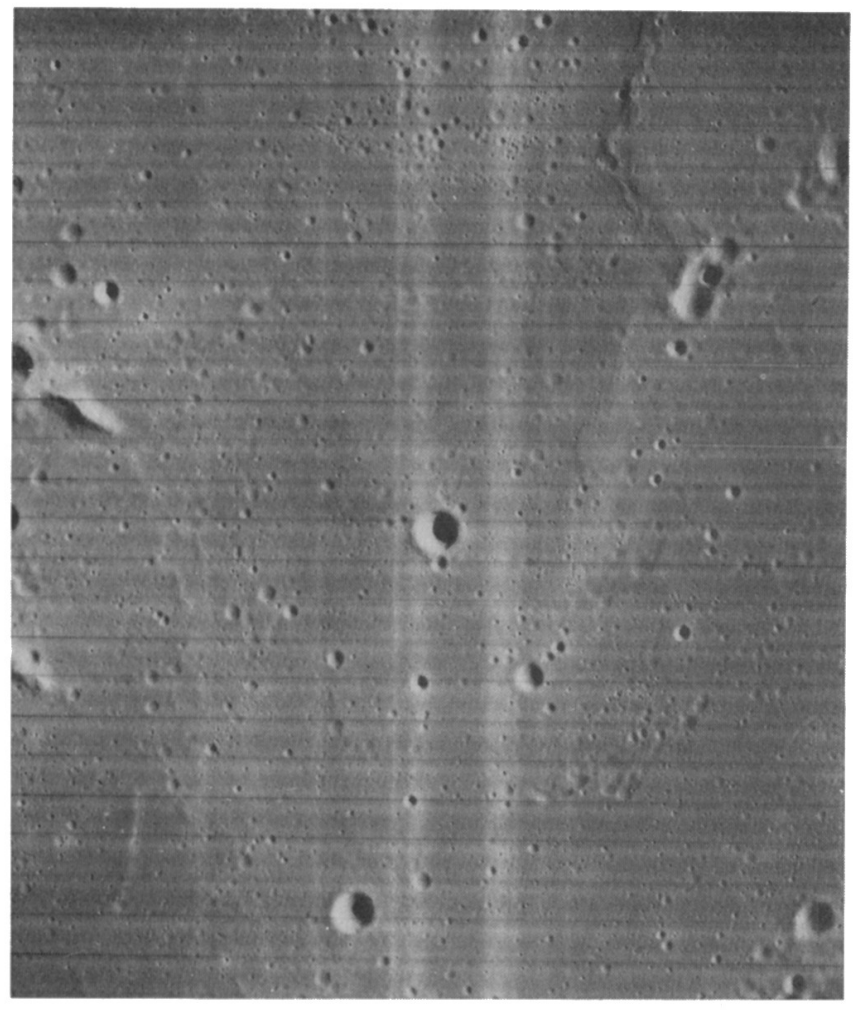

Fig. 20. 


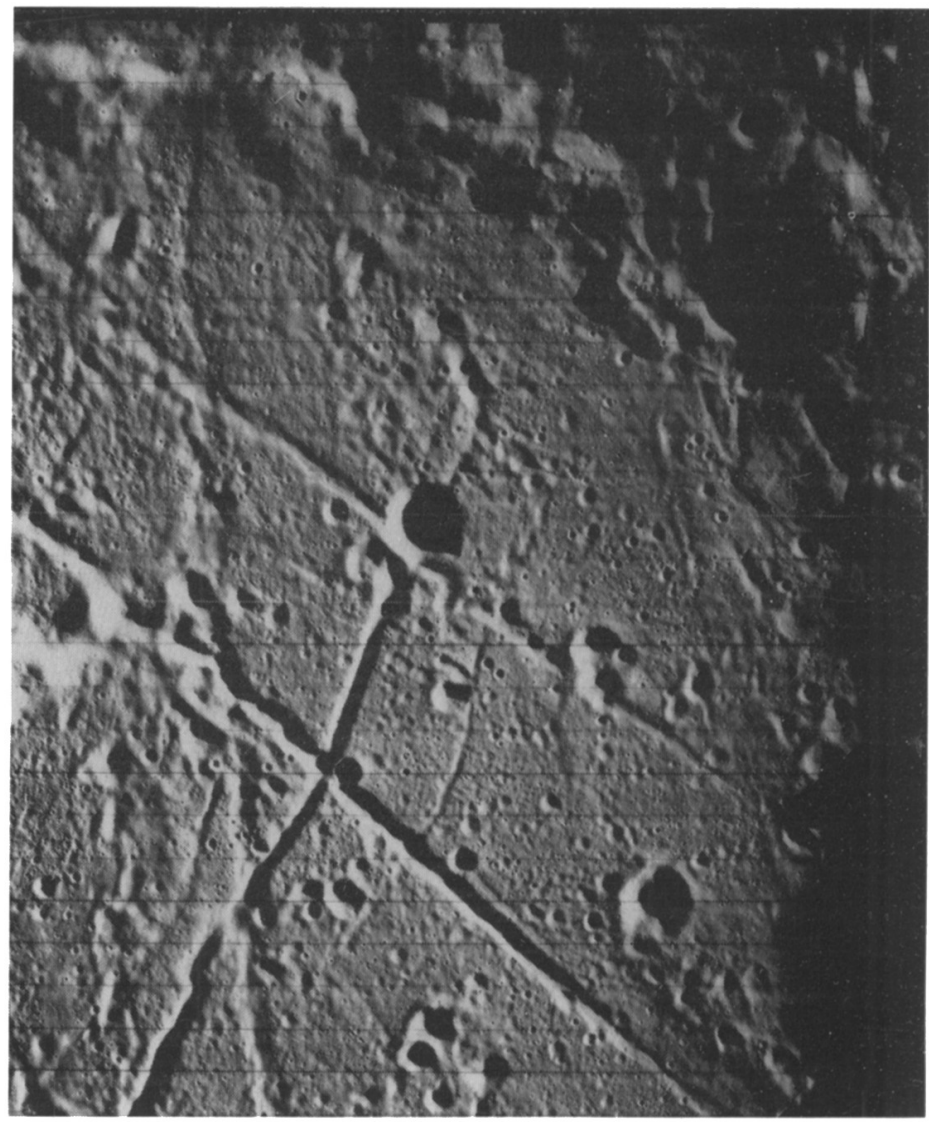

FIG. 21. 


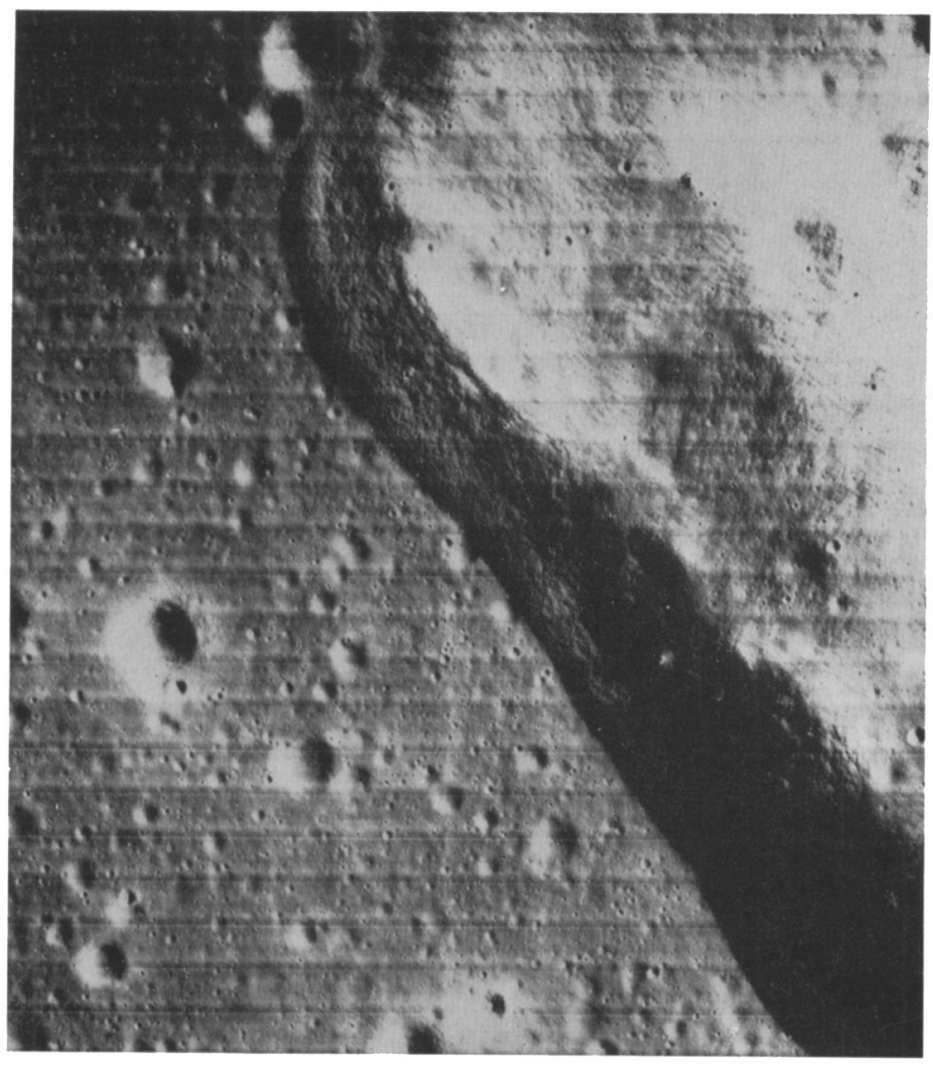

FIG. 22. 


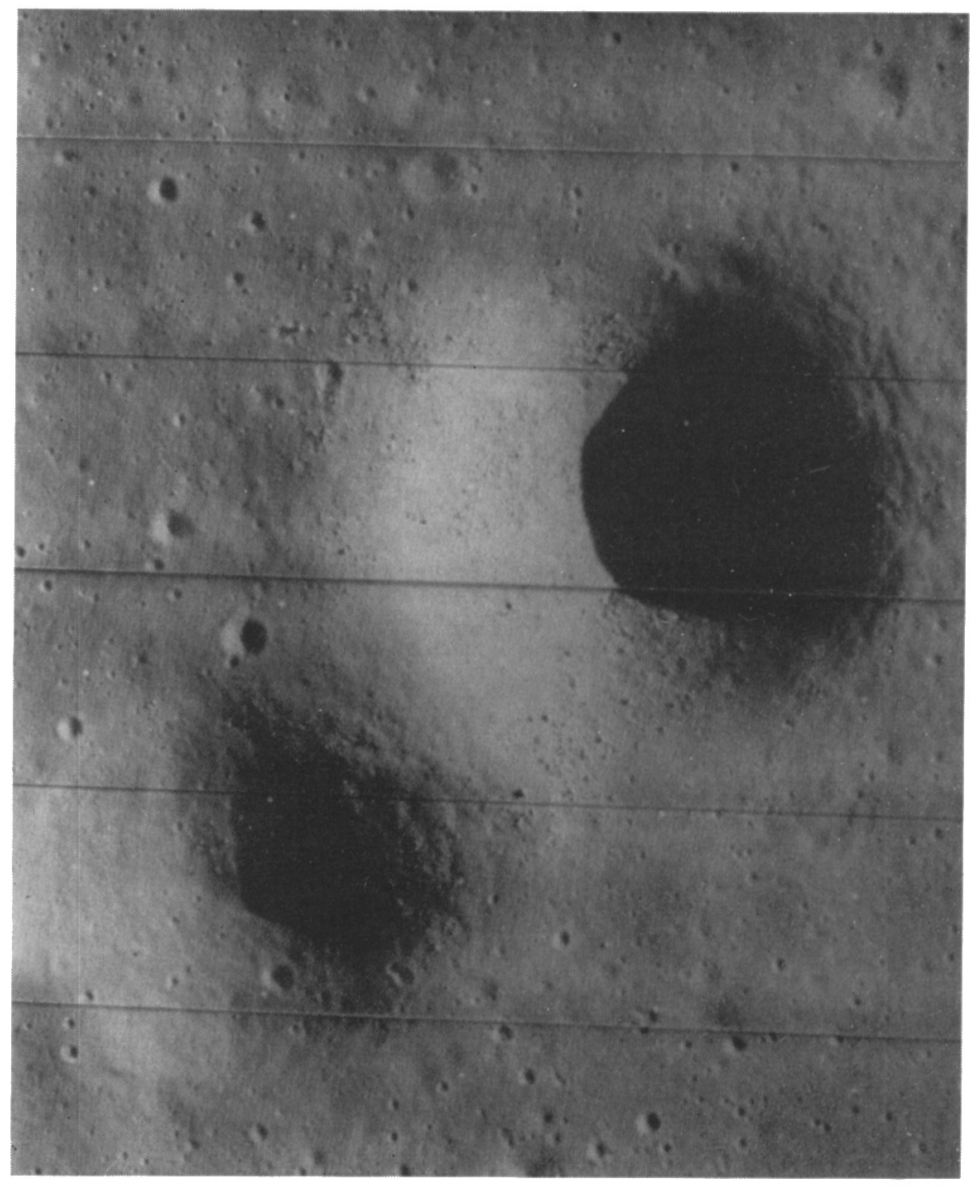

Fig. 23. 


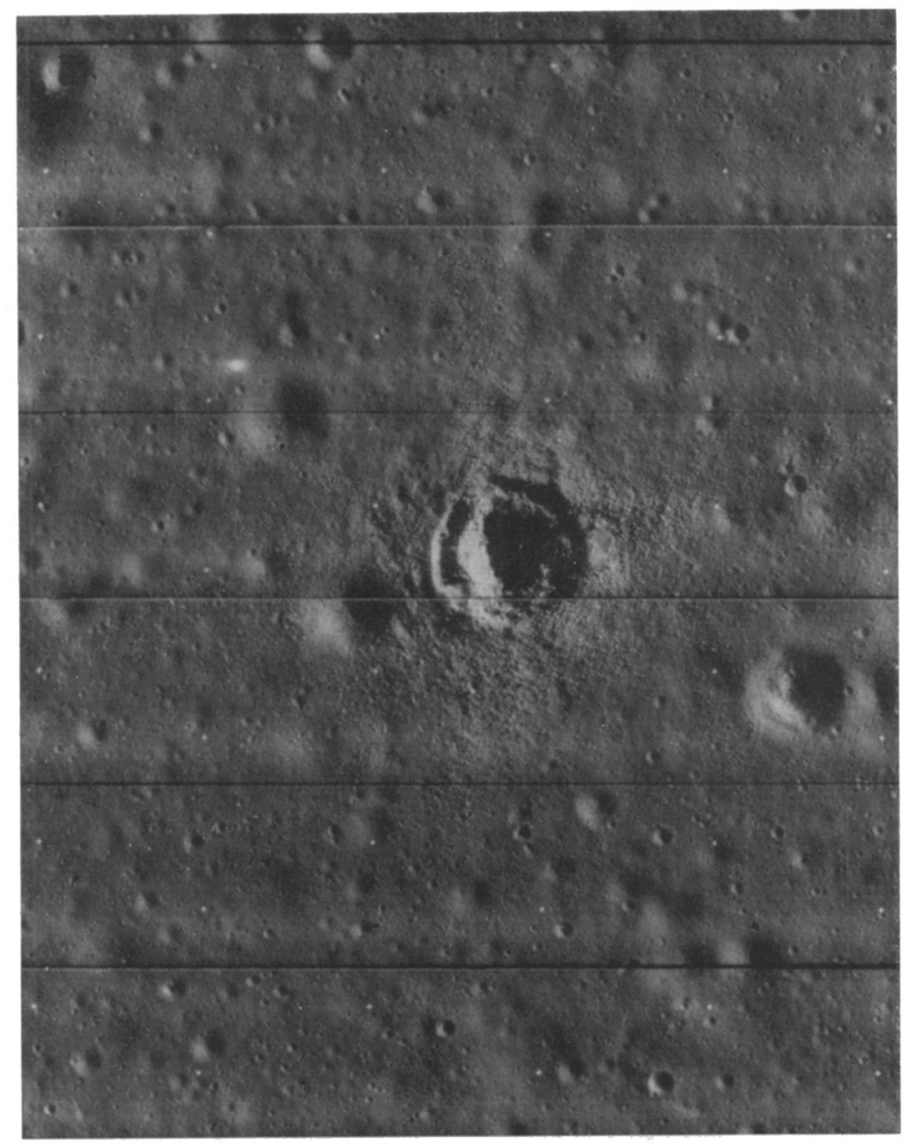

FIG. 24. 


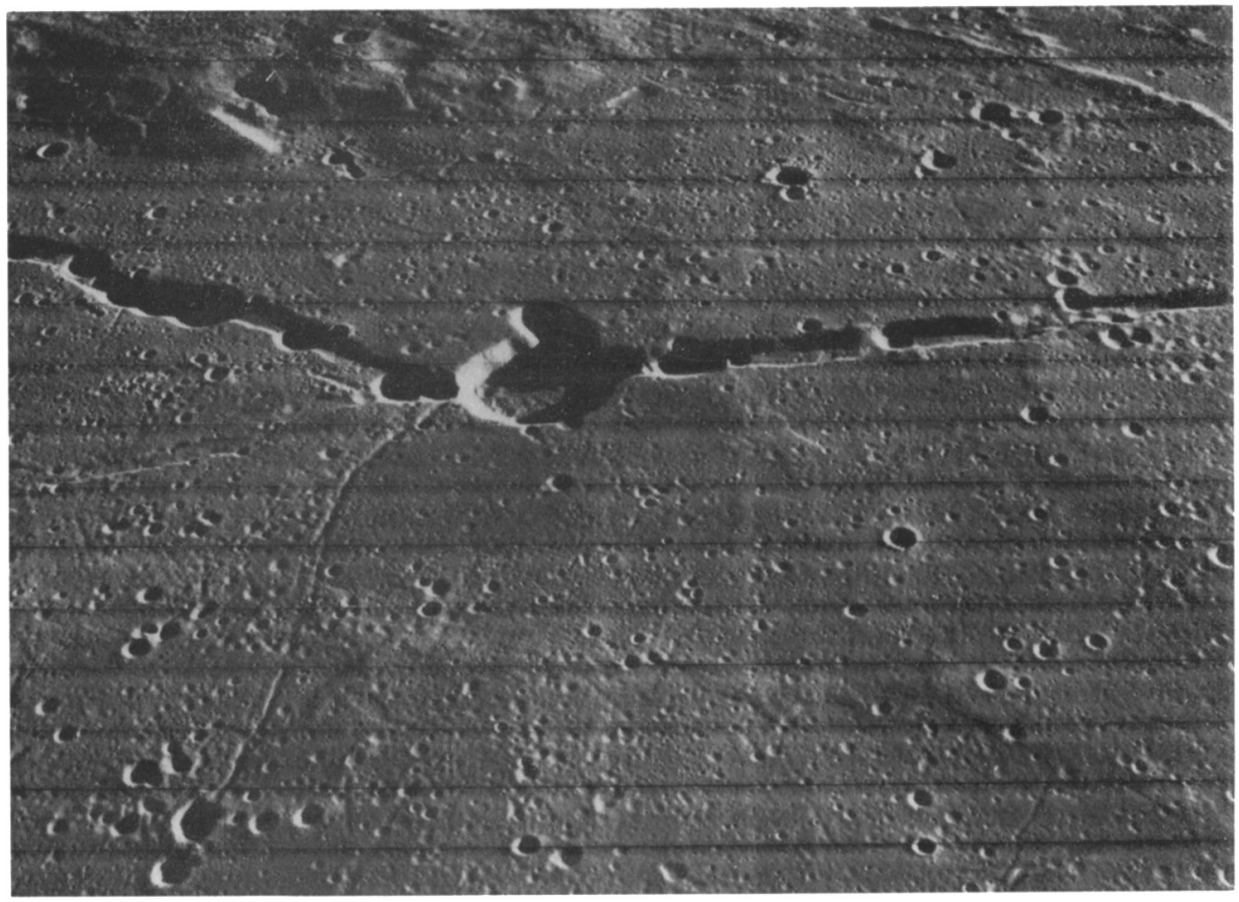

FIG. 25. 


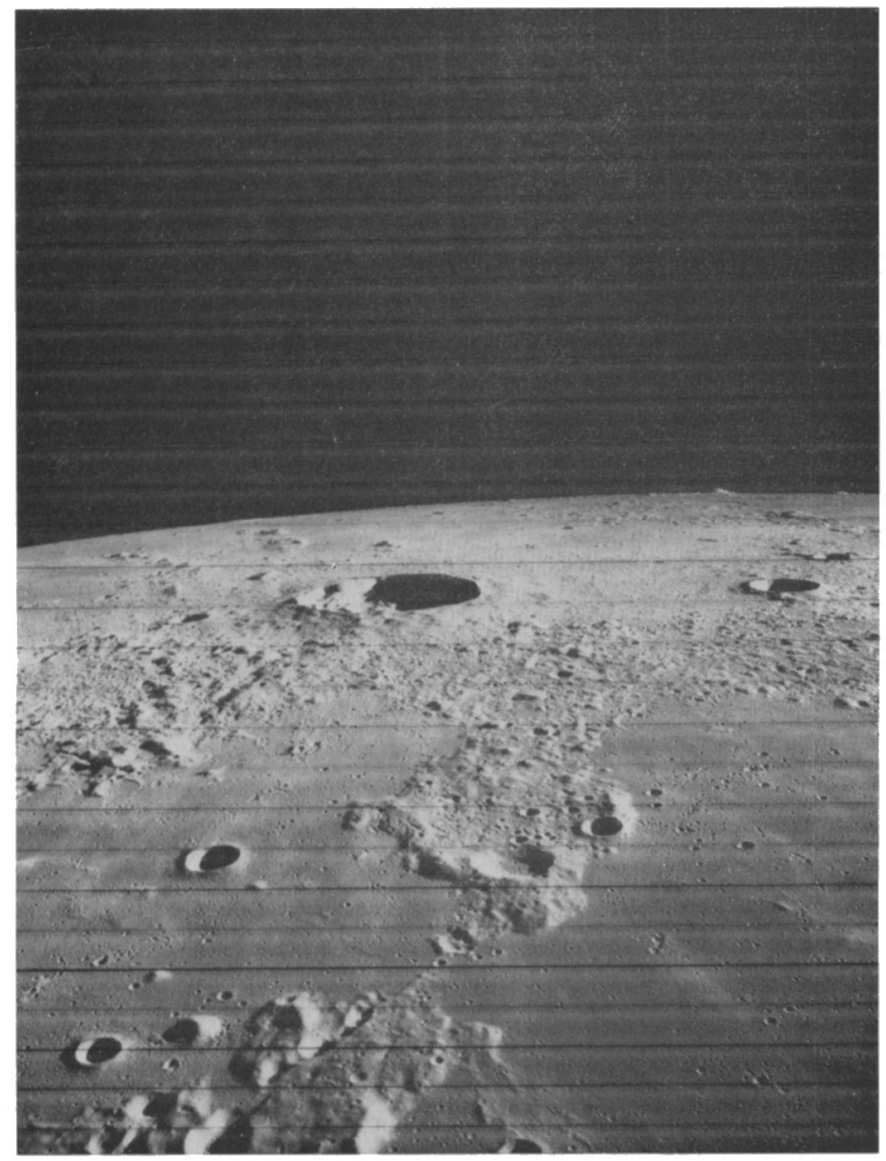

FIG. 26. 


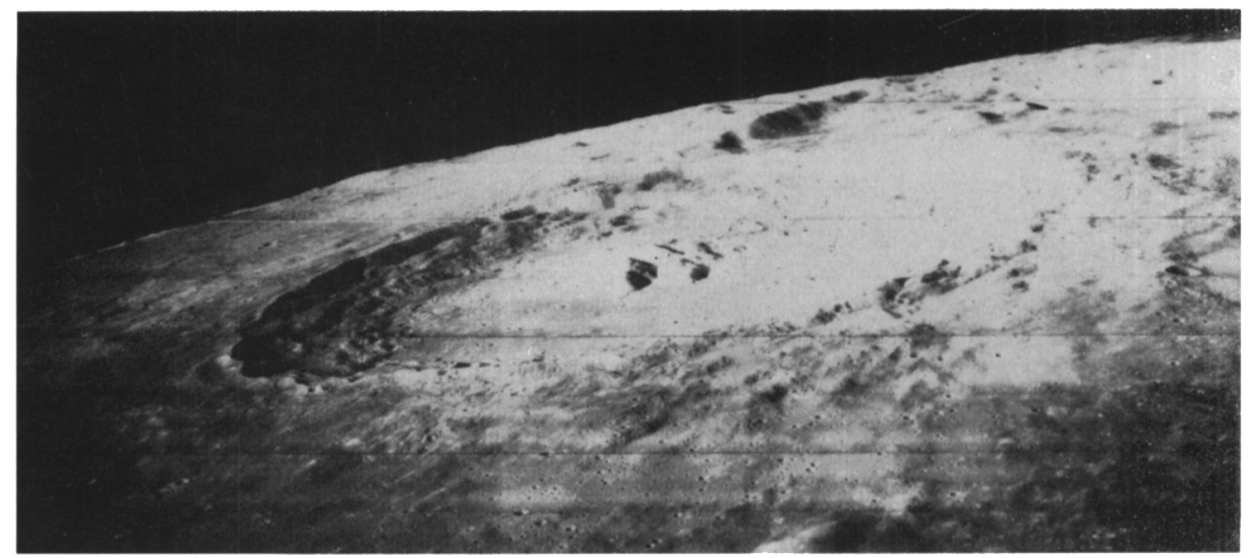

FIG. 27.

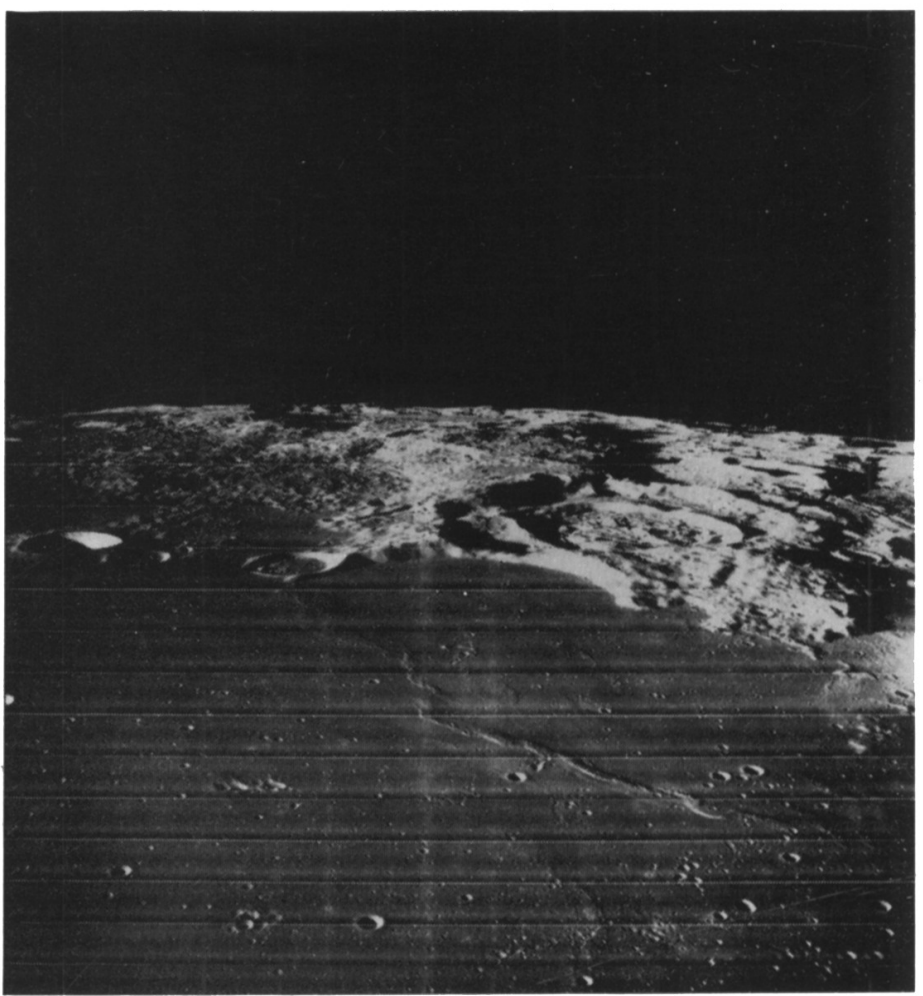

FiG. 28. 


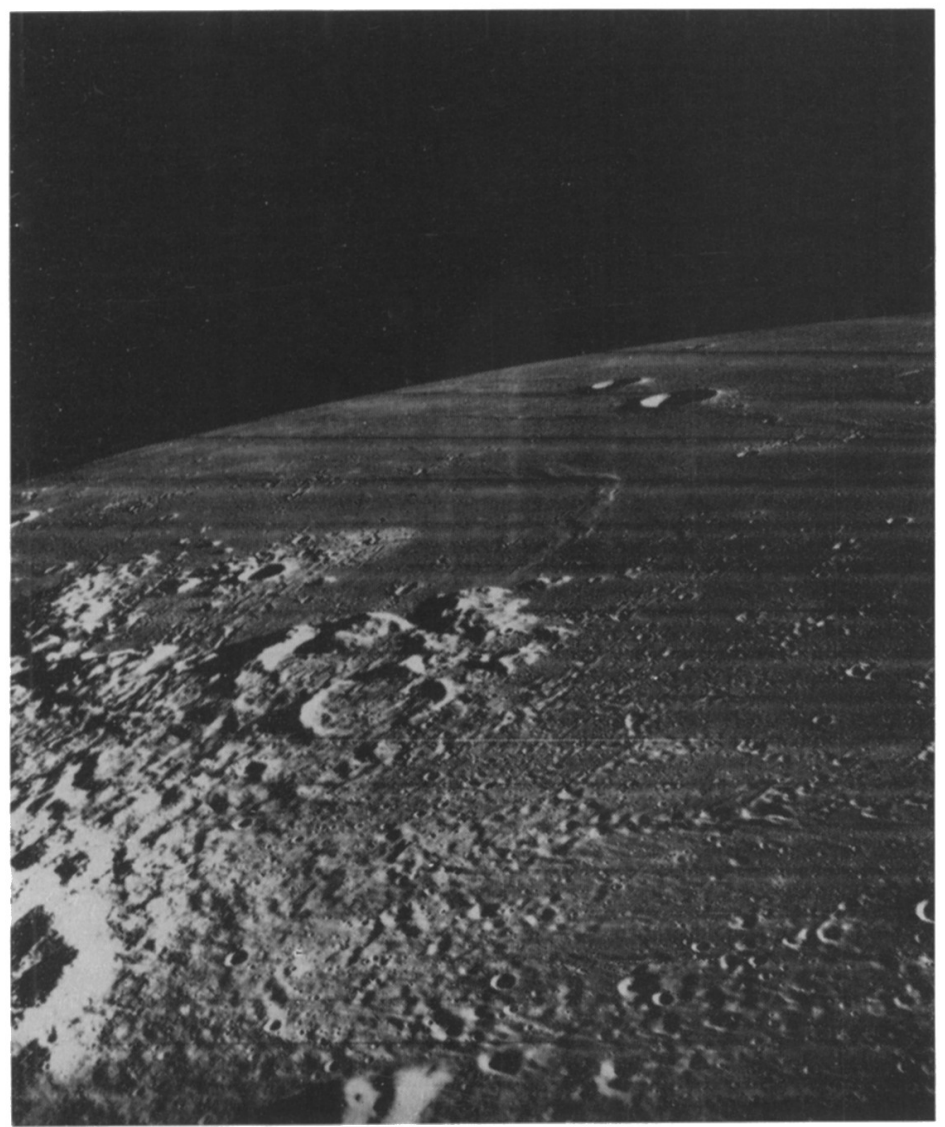

FIG. 29. 


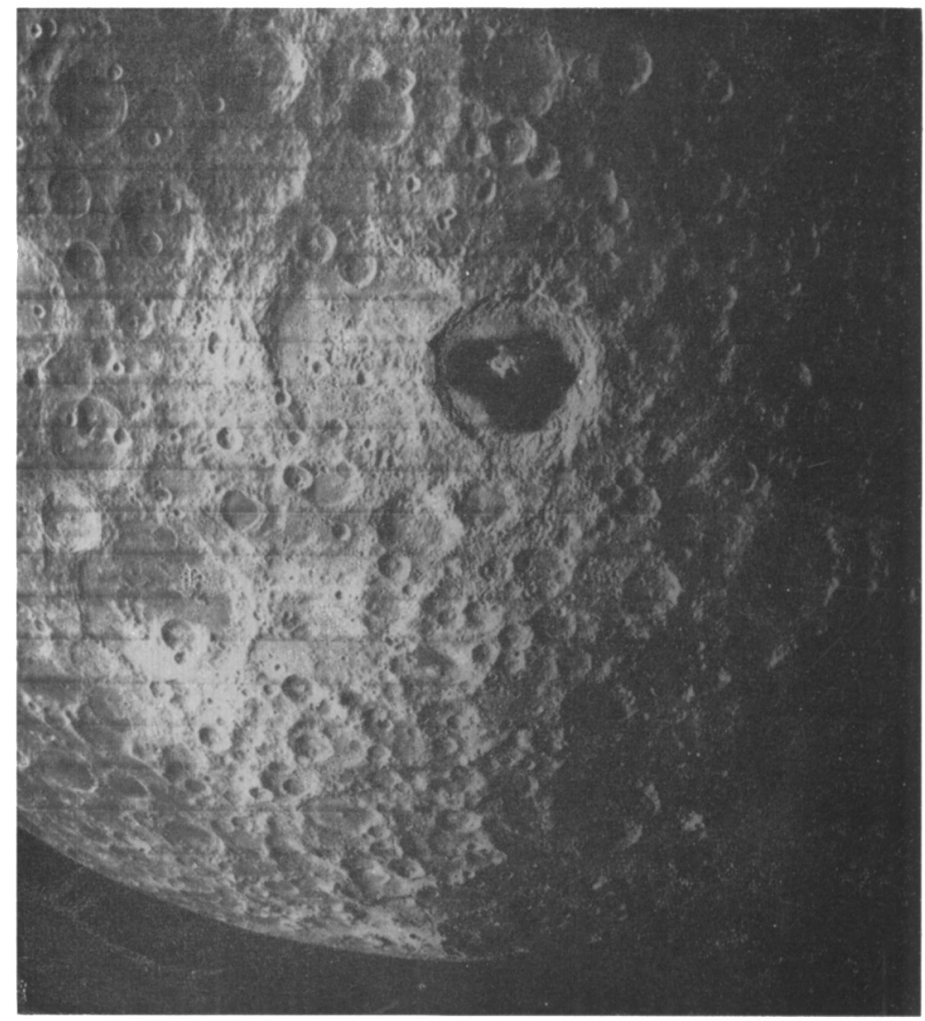

FIG. 30. 
graph. A section of the high-resolution photograph of this region is shown in Figure 31. Details of Tsiolkovsky and the surrounding region are clearly seen.

The front-side coverage of Lunar Orbiters-I - III is diagrammed in Figure 32. The closed rectangles represent vertical photographs, while the open-ended outlines represent oblique photographs.

The prime mission of Lunar Orbiter-IV was to obtain maximum photographic coverage of the lunar front side at a resolution of $100 \mathrm{~km}$ or better. To accomplish this, the orbital inclination was changed to $85^{\circ}$ and the perilune and apolune altitudes were changed to 2700 and $6100 \mathrm{~km}$, respectively. The high-resolution coverage of the front side that was obtained is shown in Figure 33. The line drawing on the right should be considered an overlay of the lunar reference mosaic on the left. Each outlined area represents a high-resolution photograph. The gaps in the coverage near the Eastern limb were to be filled in with Lunar Orbiter-V photography. Each of the highresolution photographs was a vertical photograph, that is, the center of each region was directly under the spacecraft at the time the exposure was made.

Moderate-resolution photographs from Lunar Orbiter-IV are of great interest as

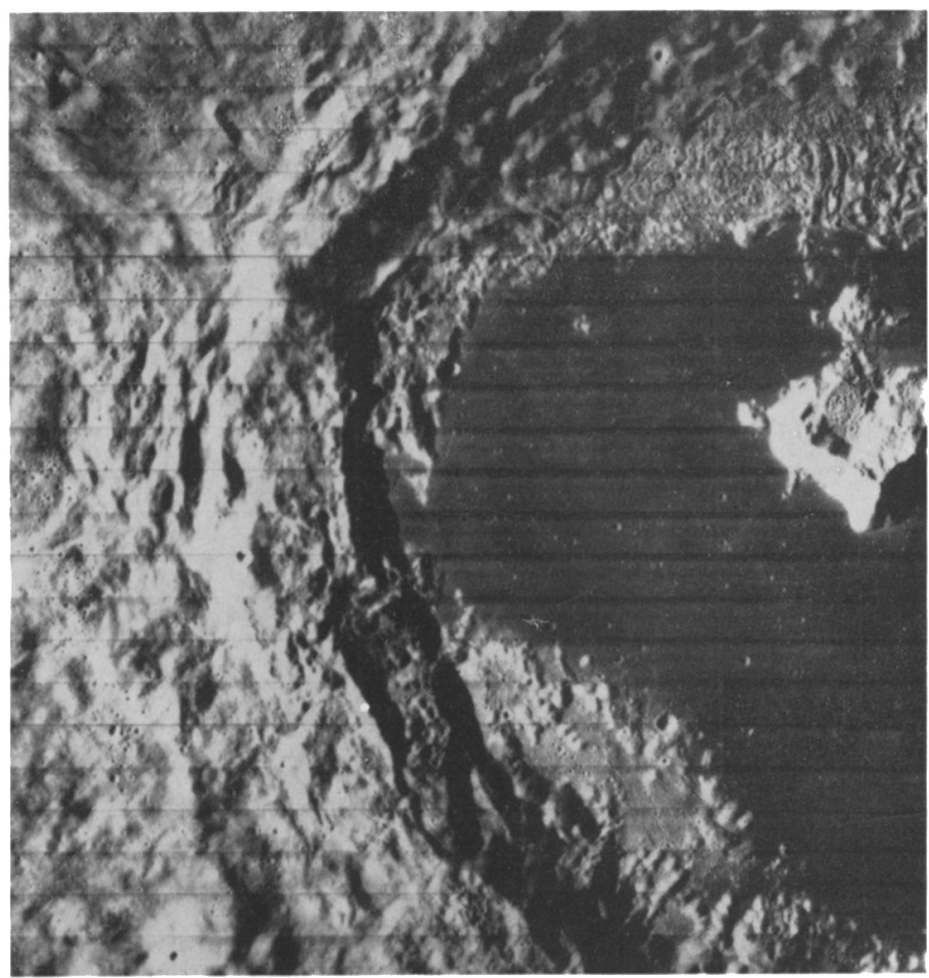

FIG. 31. 


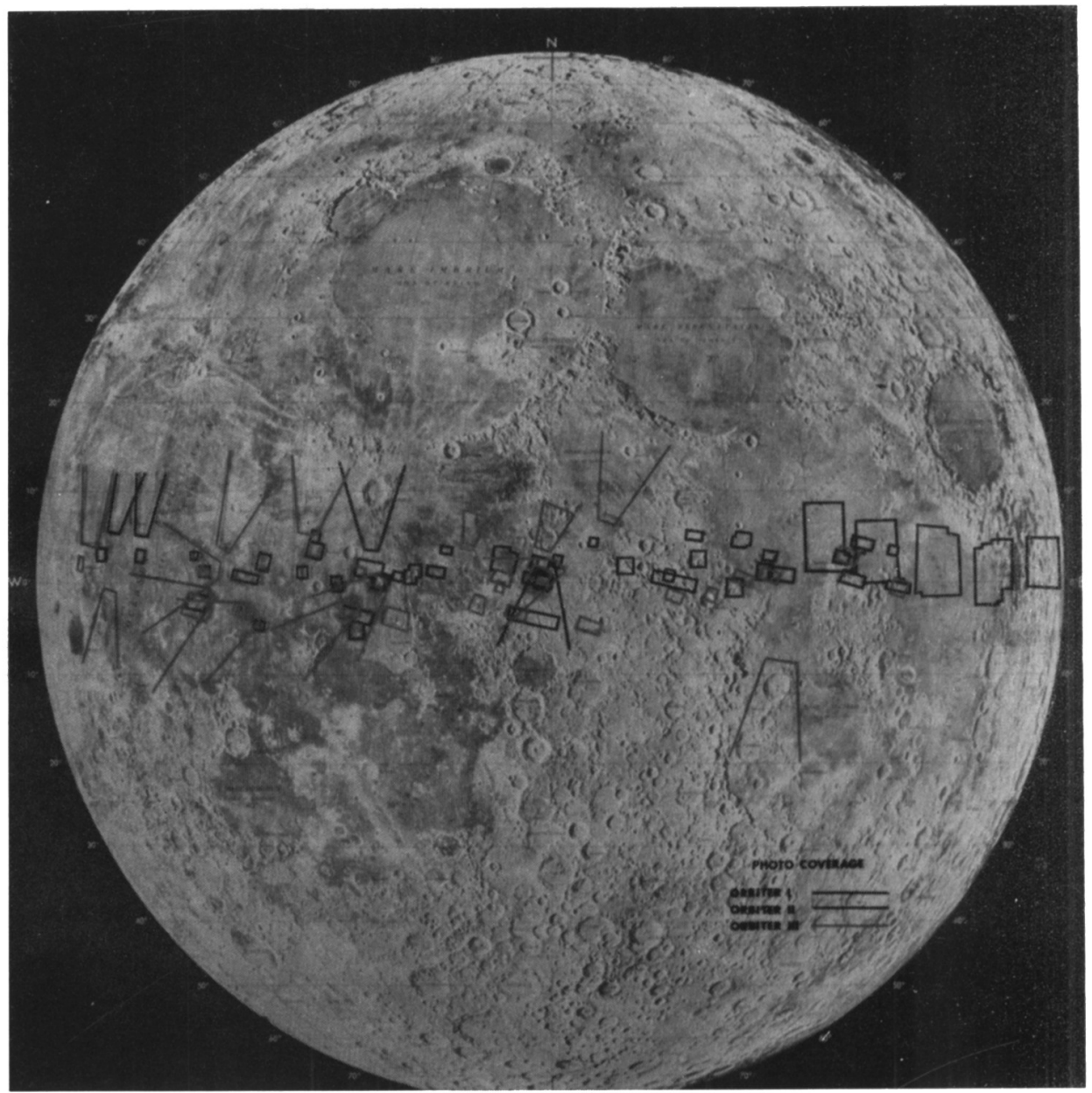

FIG. 32 . 


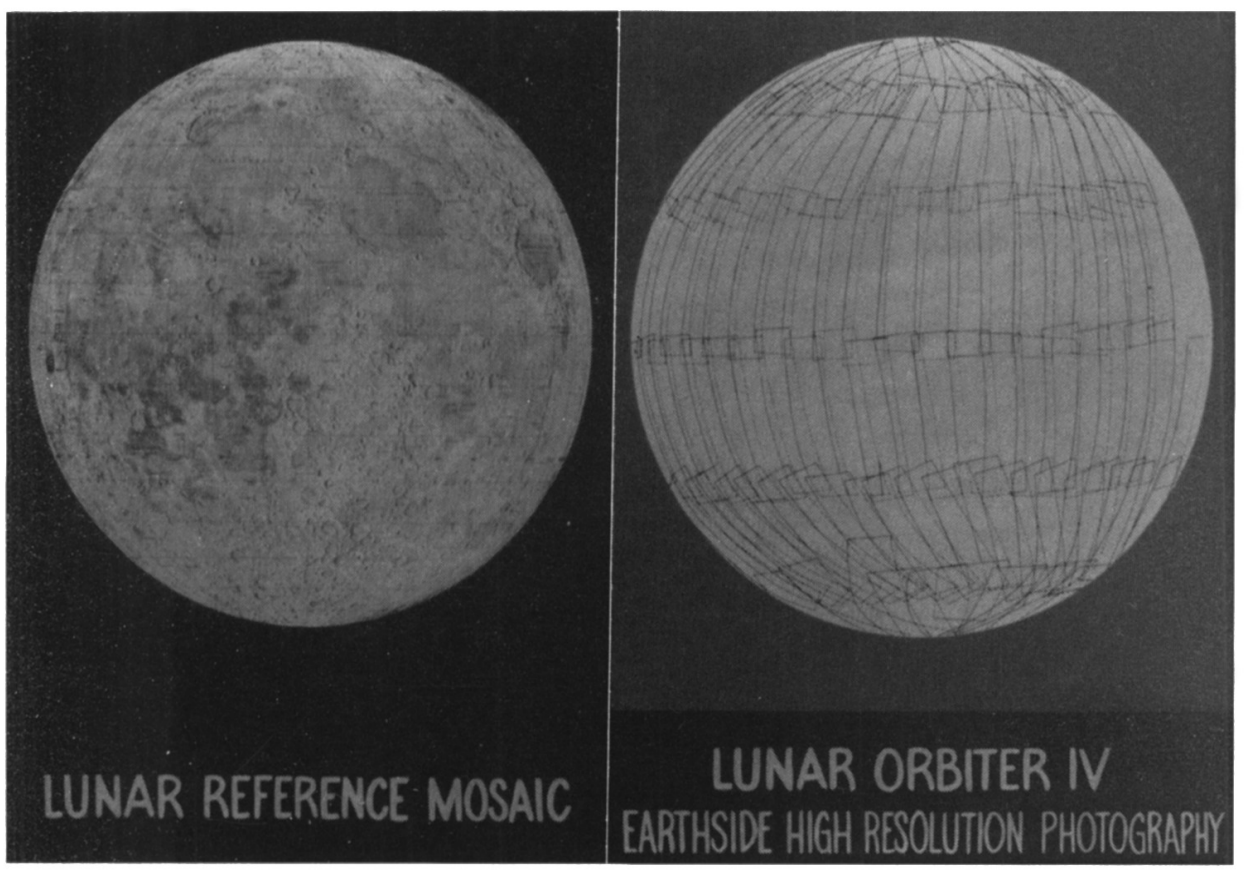

FIG. 33. 


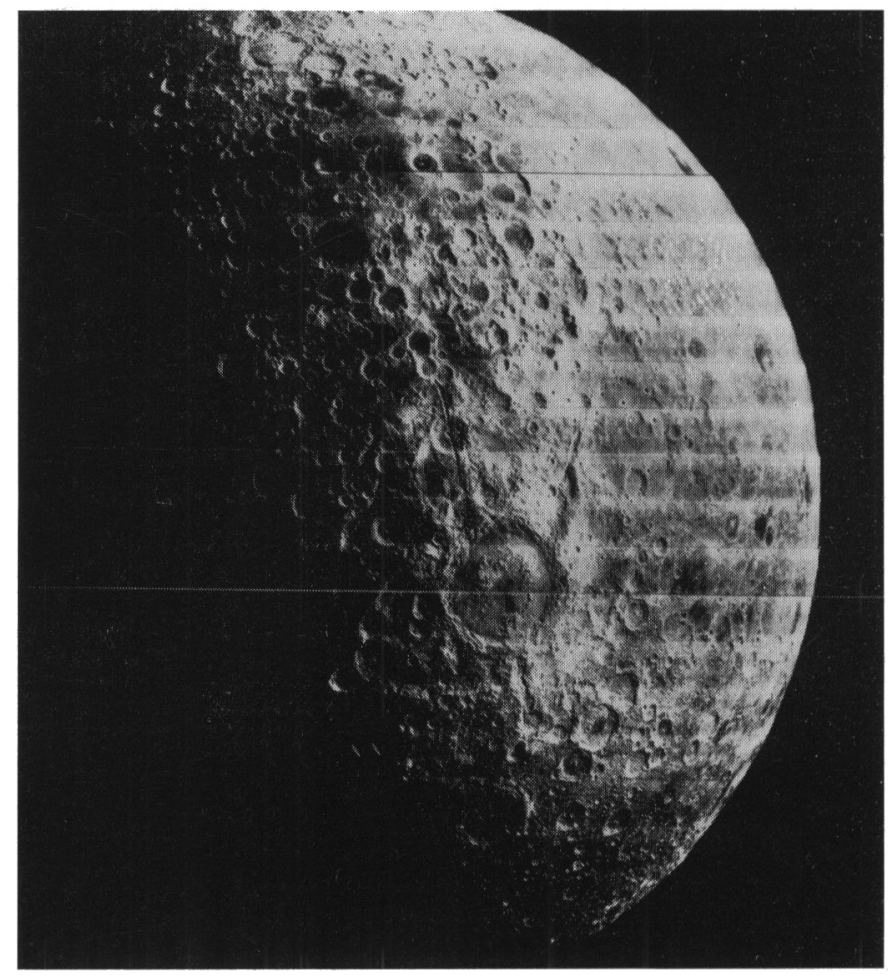

Fig. 34. 
they show the lunar disk as seen from different directions. Several of these will be shown in Figures 34-38 and, in each case, the coordinates of the center of the observed lunar disk will be given. The southeastern portion of the far side of the Moon is shown in Figure 34, coordinates $93^{\circ} \mathrm{E}, 72^{\circ} \mathrm{S}$. The long scars are newly discovered features located near the south polar region. The northern portion of the eastern limb, coordinates $98^{\circ} \mathrm{E}, 42^{\circ} \mathrm{N}$, is seen in Figure 35. Mare Smythii is visible near the bottom of the picture. In the next two figures, the Moon is observed from a longitude near zero. In Figure 36, the northern region of the Moon is seen, coordinates $13^{\circ} \mathrm{W}, 72^{\circ} \mathrm{N}$, with Mare Imbrium at the bottom of the picture. A view from a southern latitude, coordinates $6^{\circ} \mathrm{W}, 72^{\circ} \mathrm{S}$, is seen in Figure 37 with Mare Nubium at the top of the picture. This series is concluded with one view of the western limb. Figure 38, coordinates $89^{\circ} \mathrm{W}, 14^{\circ} \mathrm{S}$, shows a spectacular view of Mare Orientale. This outstanding feature is partially observable on Earth-based photographs as seen in Figure 39. It is not difficult to recognize the corresponding features in the two photographs. Much of the area surrounding Mare Orientale shows surface structure not observed over other large areas of the lunar surface. Two examples of this unusual surface structure are shown in Figures 40 and 41 . The appearance is very similar to that of a mud flow.

The next group of pictures show sections of some of the high-resolution photographs containing well-known lunar features. The Alpine Valley and a portion of the lunar Alps are shown in Figure 42. A sinuous rille is clearly seen running the length of the Alpine Valley. The crater Eratosthenes and the mare region surrounding it are seen in Figure 43. The line of white dots in the lower right is a flaw produced during the processing of the film in the spacecraft. The crater Archimedes and surroundings are shown in Figure 44, while Figure 45 shows the crater Tycho and the neighboring highland region. The crater Aristarchus, of great interest because of reported gaseous emissions emanating from it, is seen in Figure 46.

Lunar Orbiter-IV photography included a limited coverage of the lunar far side. Added to the earlier coverage were details of the eastern limb and the polar regions. The combined coverage of the far side by the first four orbiters is shown in Figure 47. Approximately $70 \%$ of the hemisphere was covered at a resolution greater than would be obtainable from Earth if this side were ever turned in that direction. The Lunar Orbiter- $\mathrm{V}$ spacecraft obtained sufficient additional far-side coverage to fill in most of the blank regions. There is presently greater than $95 \%$ coverage of the lunar far side but at varying resolution.

Based on the Lunar Orbiter photography, the Aeronautical Chart and Information Center has prepared a chart of the lunar far-side at the request of NASA. The chart consists of a Mercator projection for the latitude range from $48^{\circ} \mathrm{N}$ to $48^{\circ} \mathrm{S}$ and Gnomonic projections of the polar regions down to a latitude of $48^{\circ}$. The chart was printed in two sizes, 1:5000000 and 1:10000000 which are identical except for scale. A photograph of the 1:10000000 scale chart is shown in Figure 48. Details in the region from $105^{\circ}$ to approximately $130^{\circ} \mathrm{W}$ longitude were based on U.S.S.R. Zond-III 


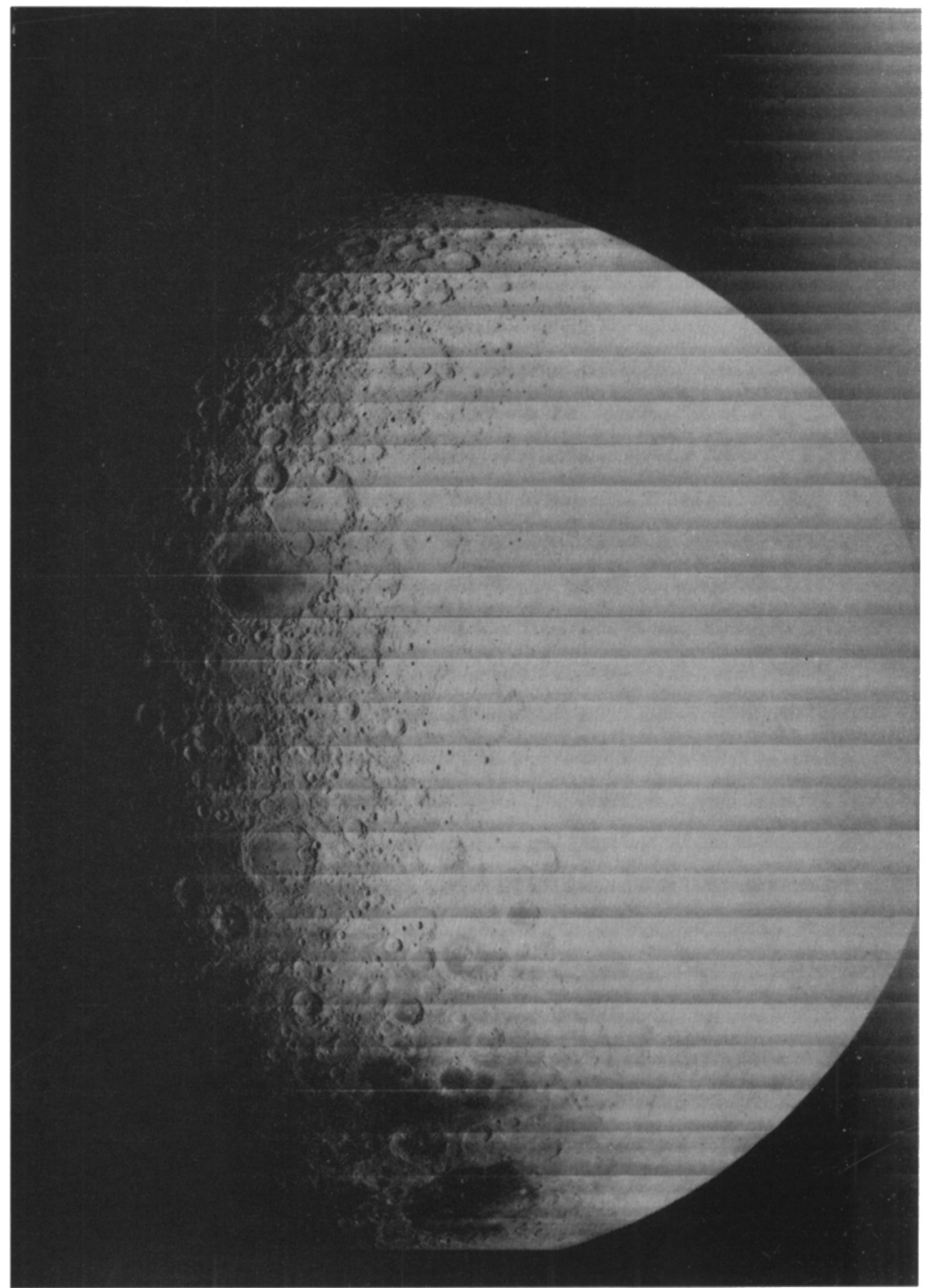

FIG. 35 . 


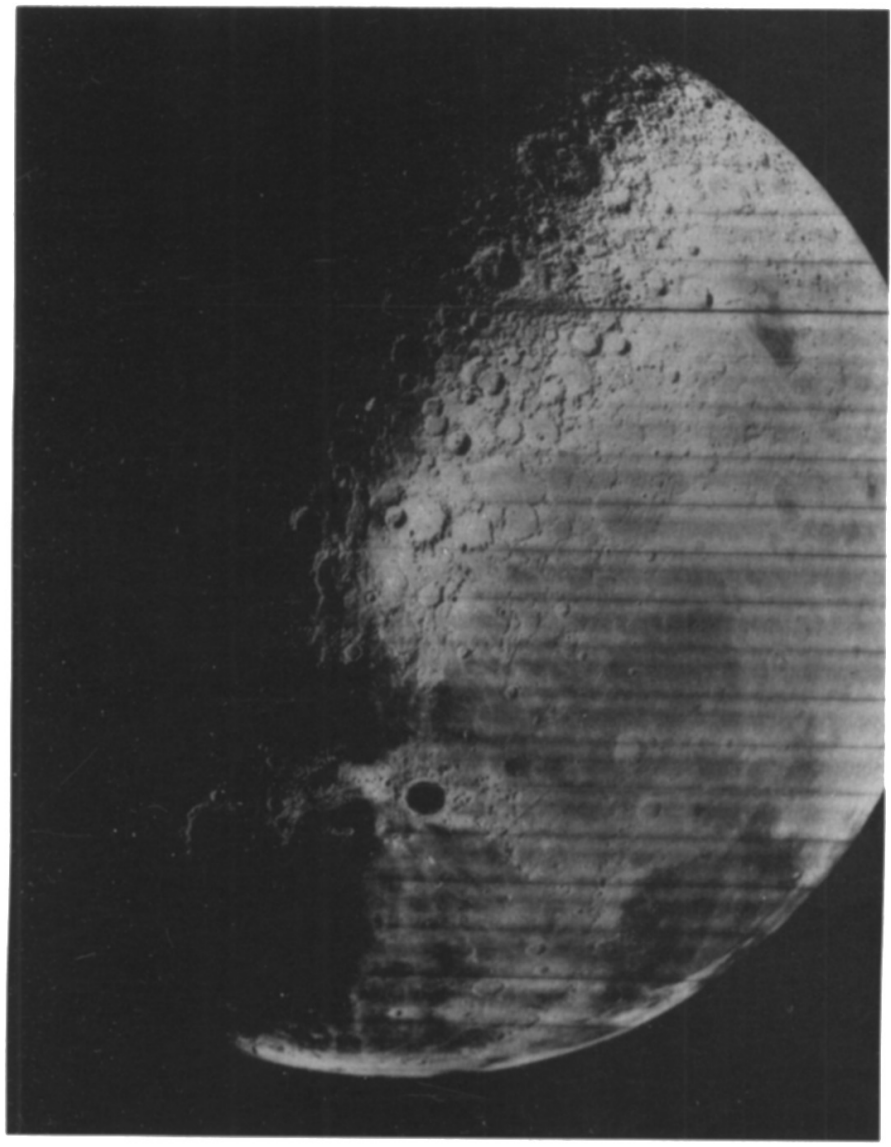

FIG. 36 . 


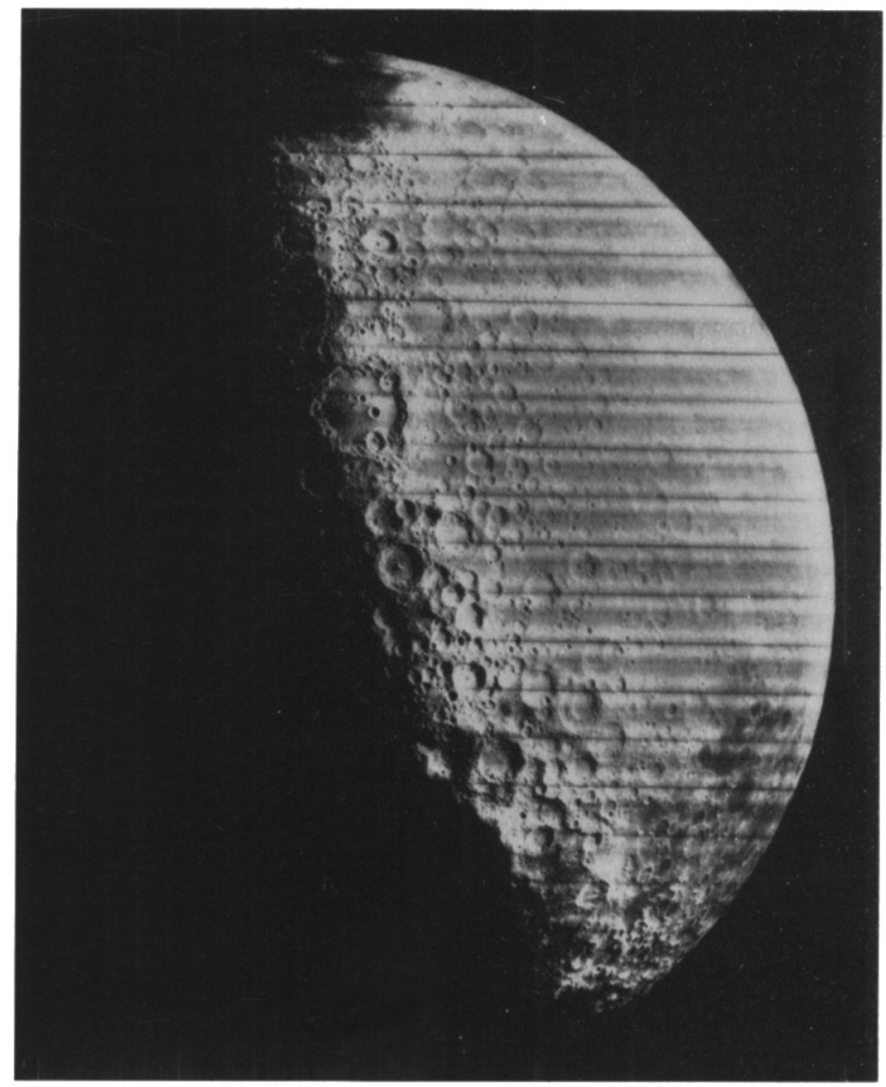

FIG. 37. 


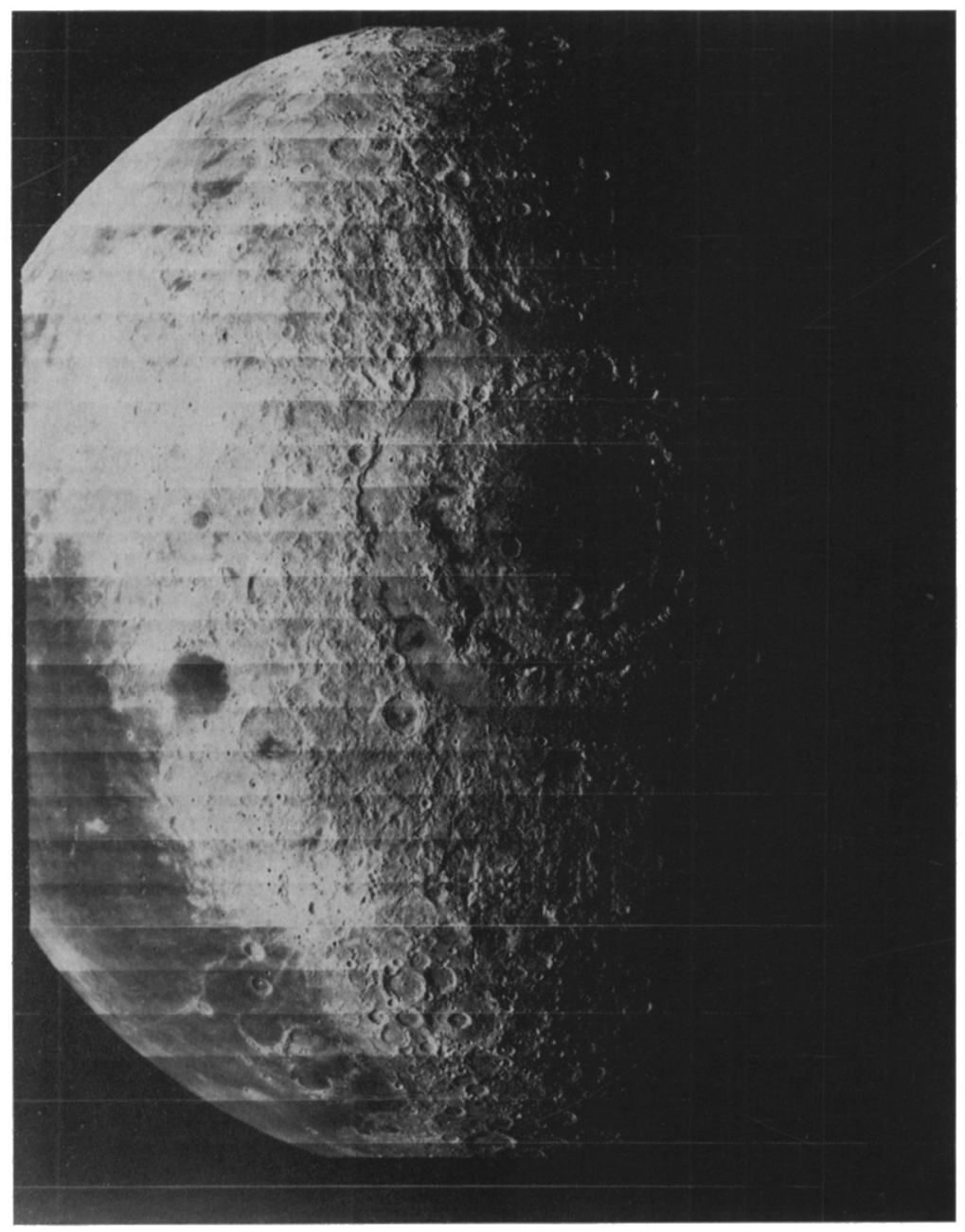

FIG. 38. 


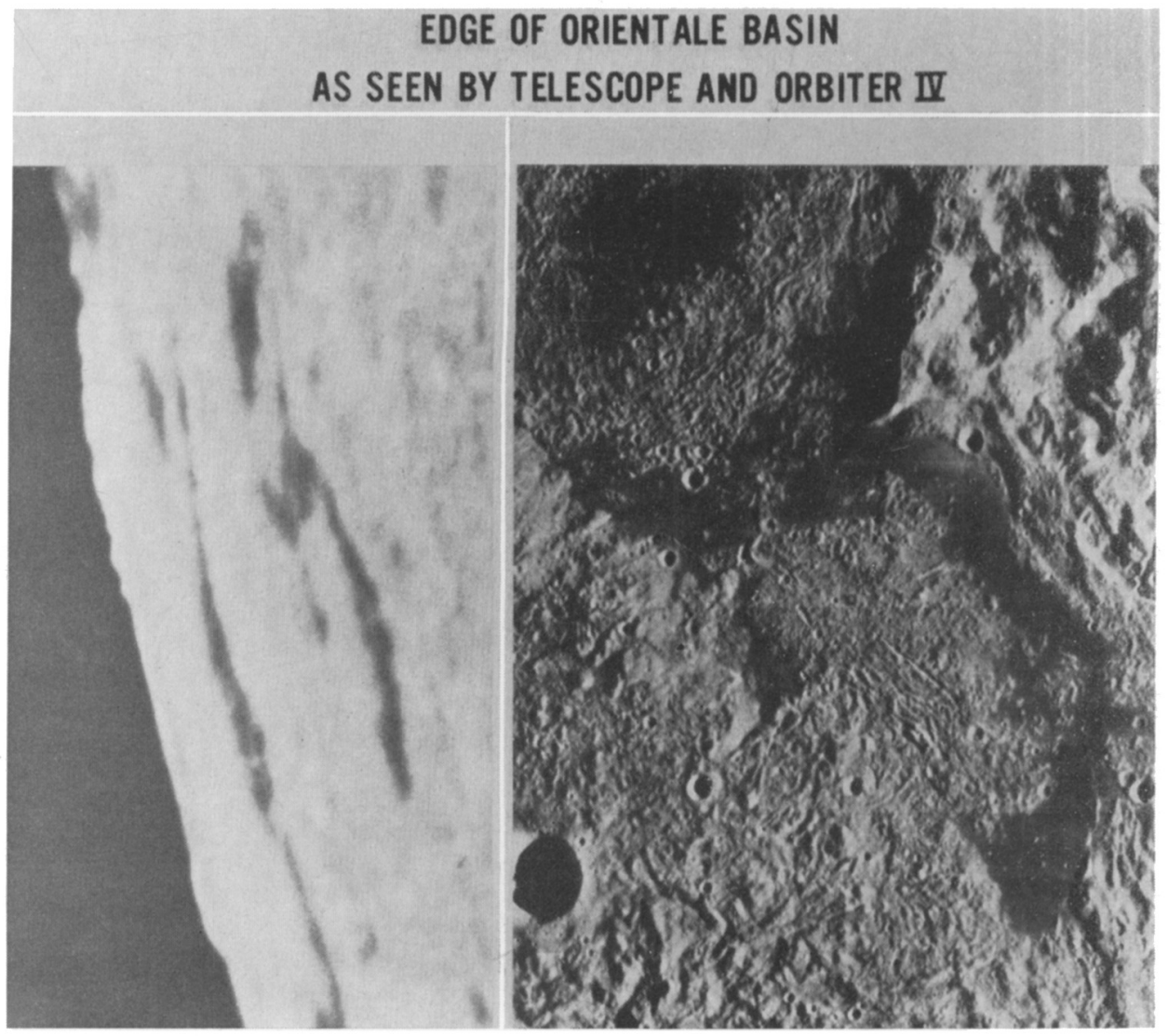

FIG. 39. 


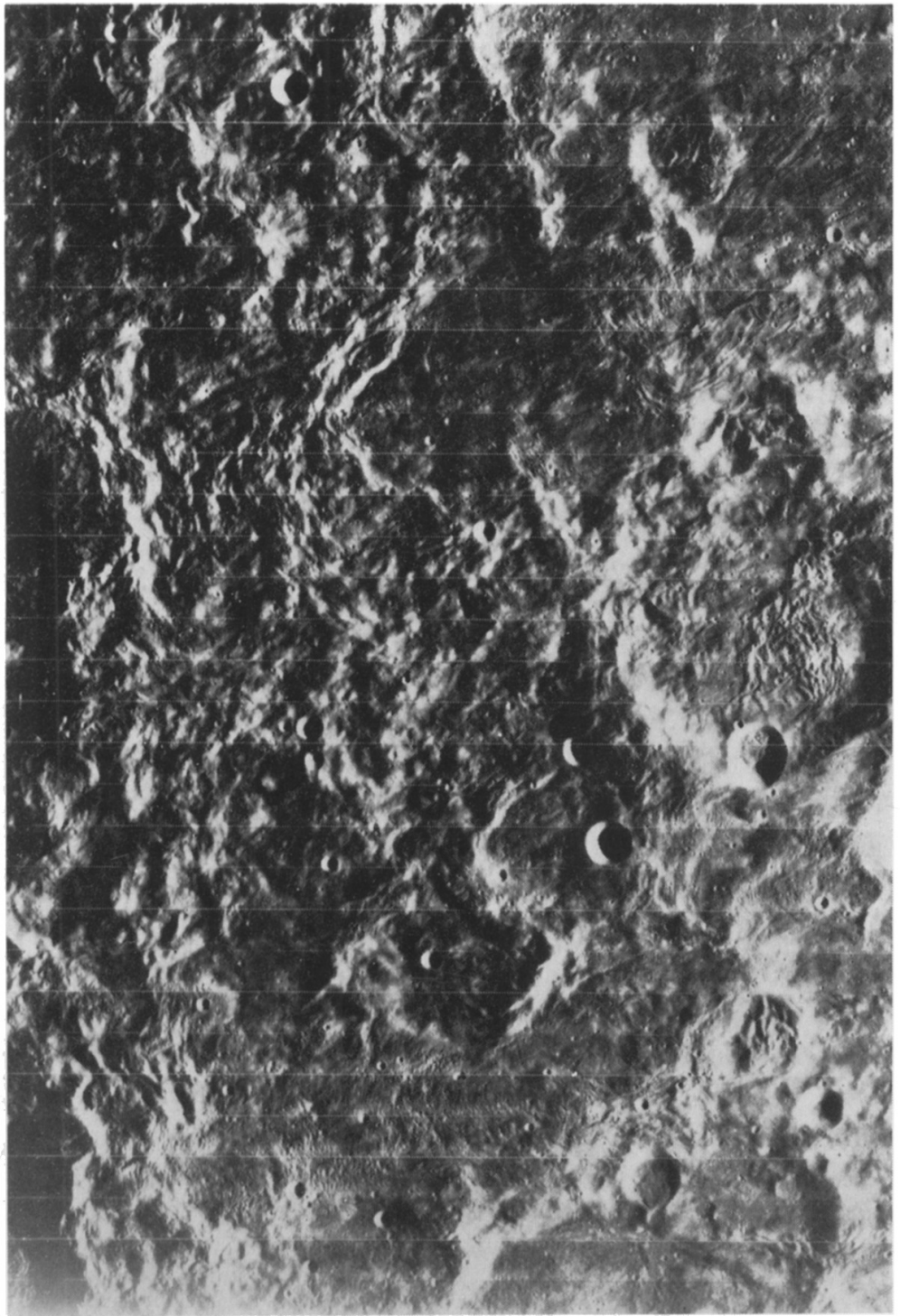

FIG. 40. 


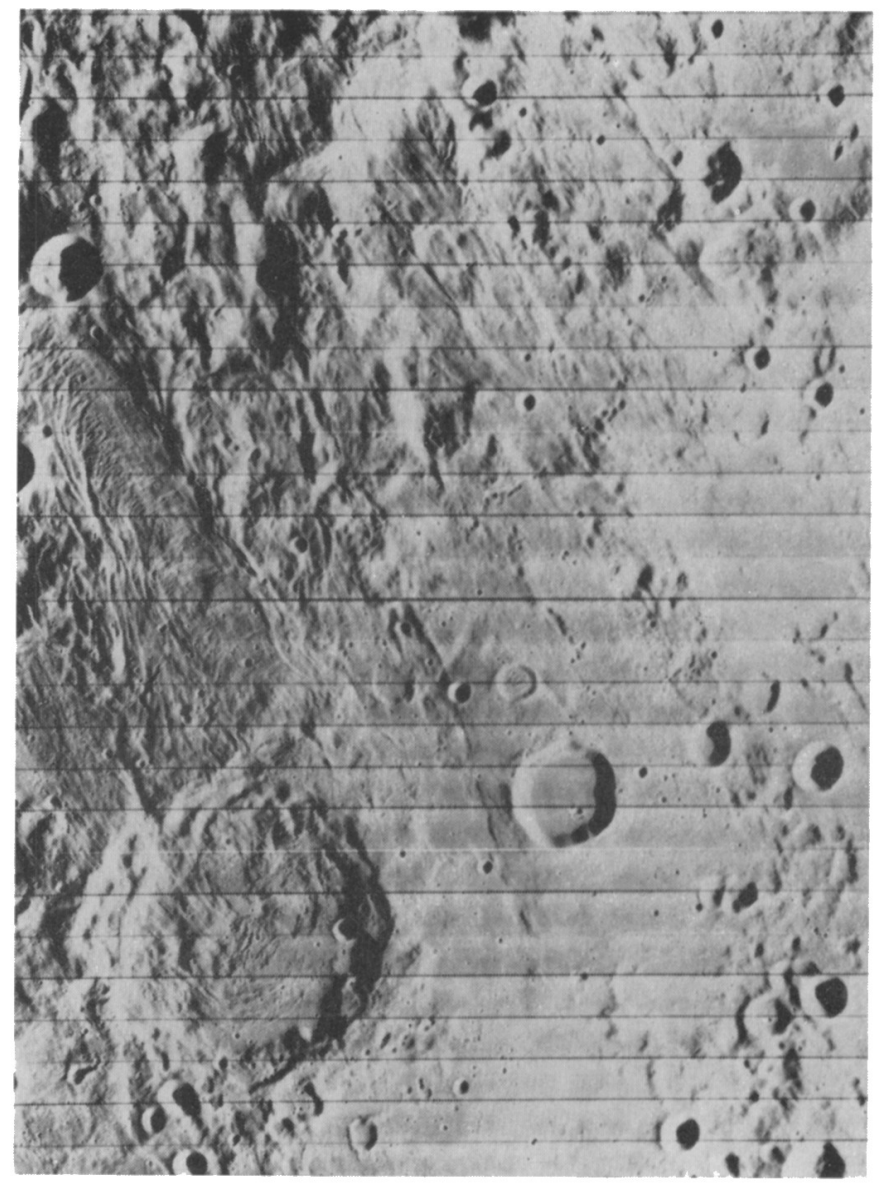

FIG. 41. 


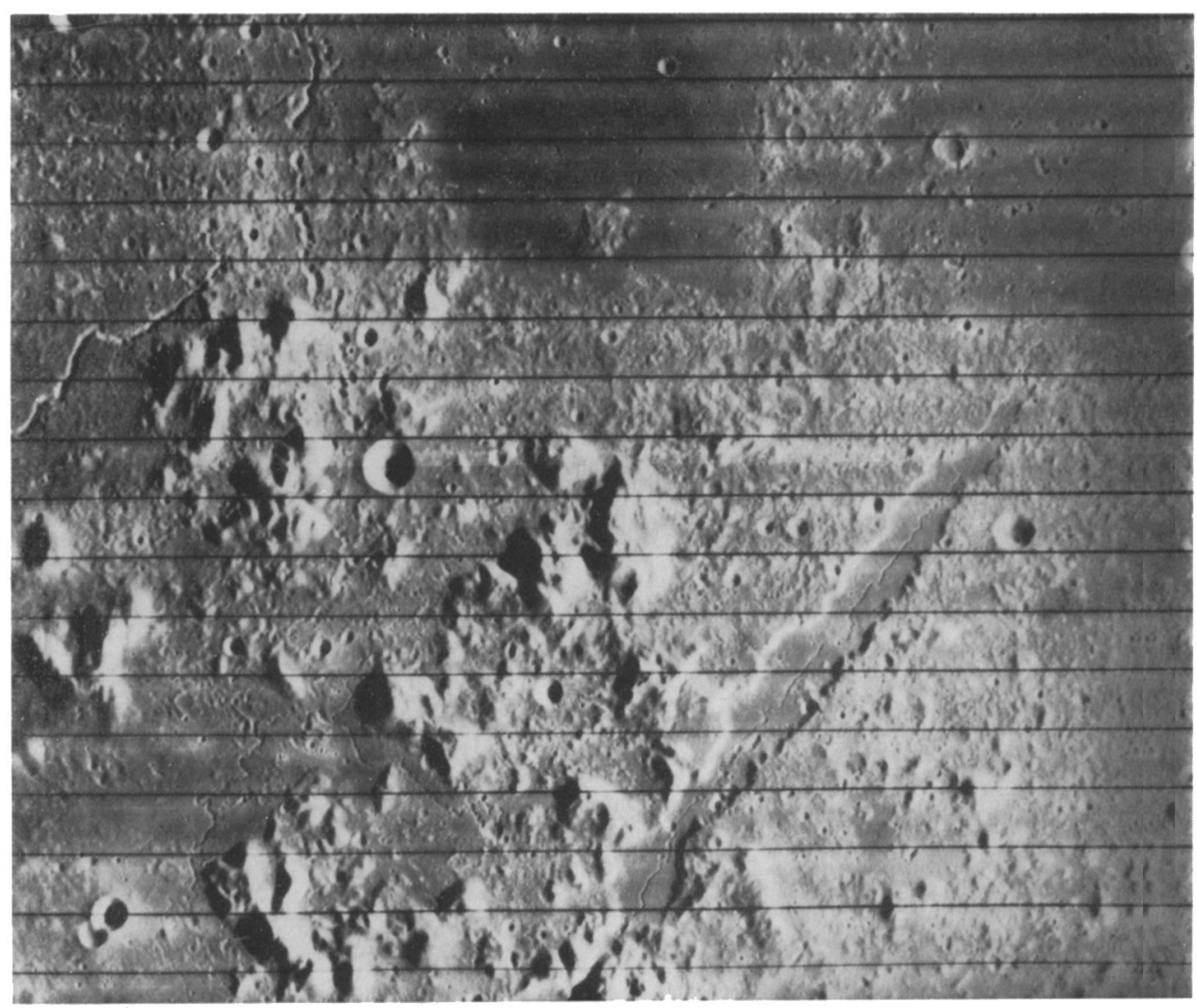

FIG. 42. 


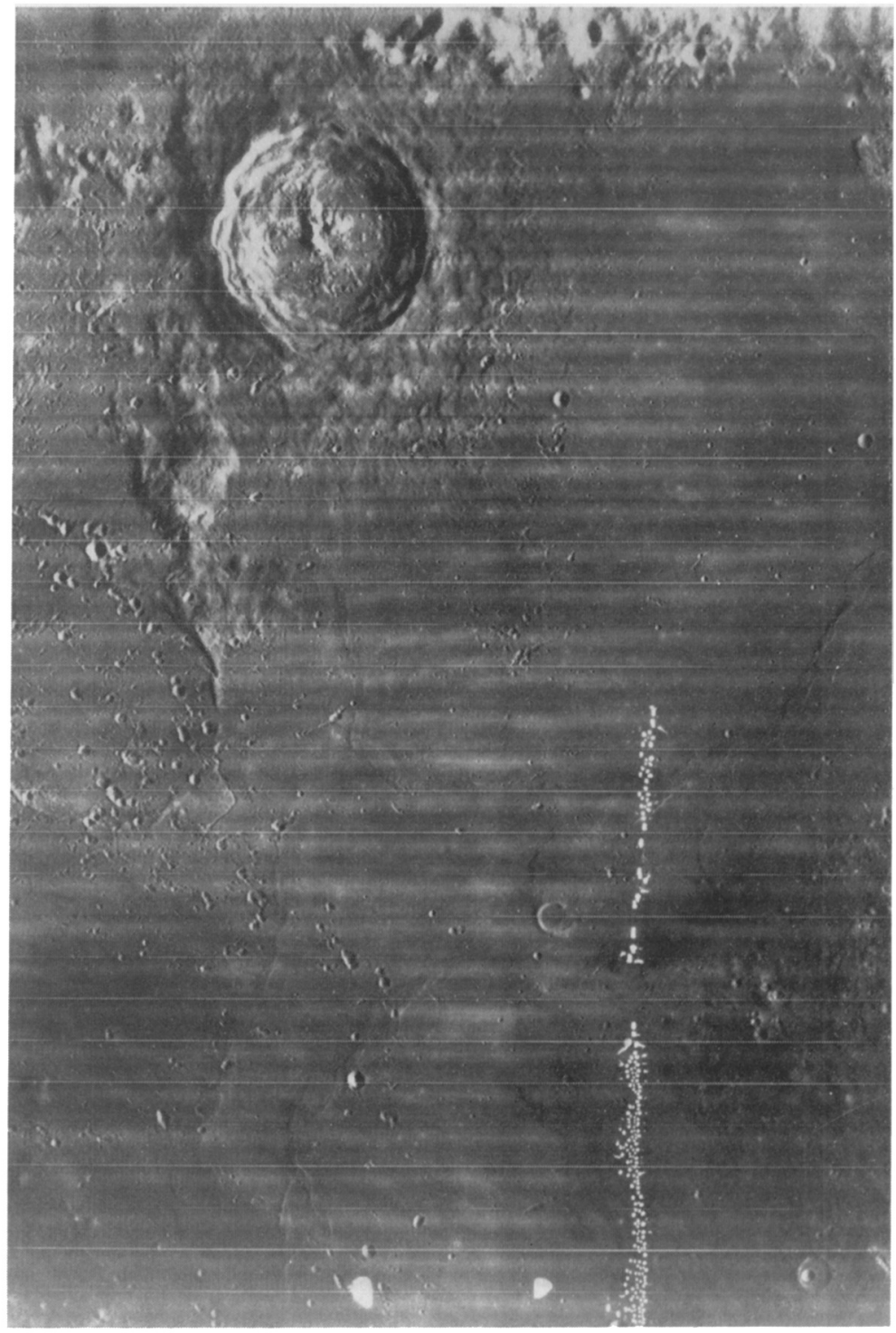

FIG. 43. 


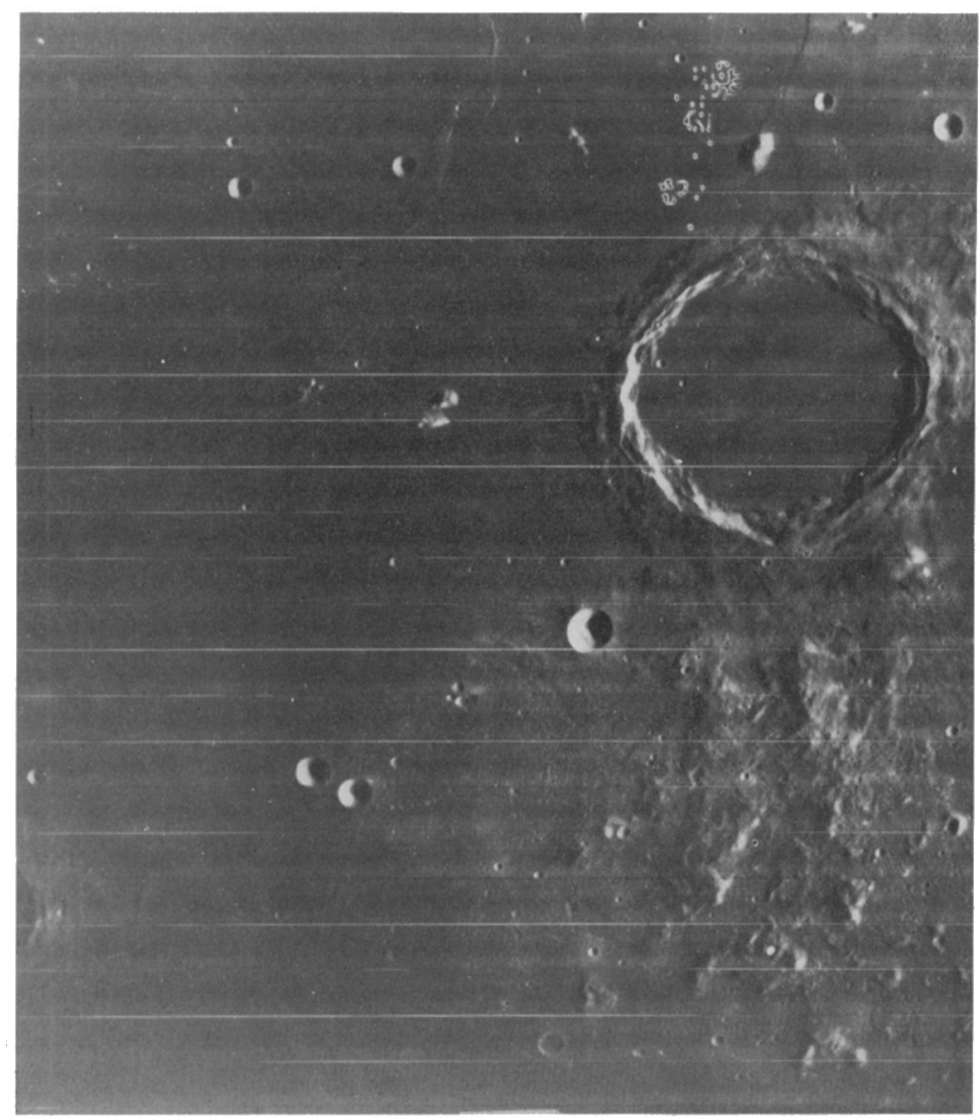

FIG. 44. 


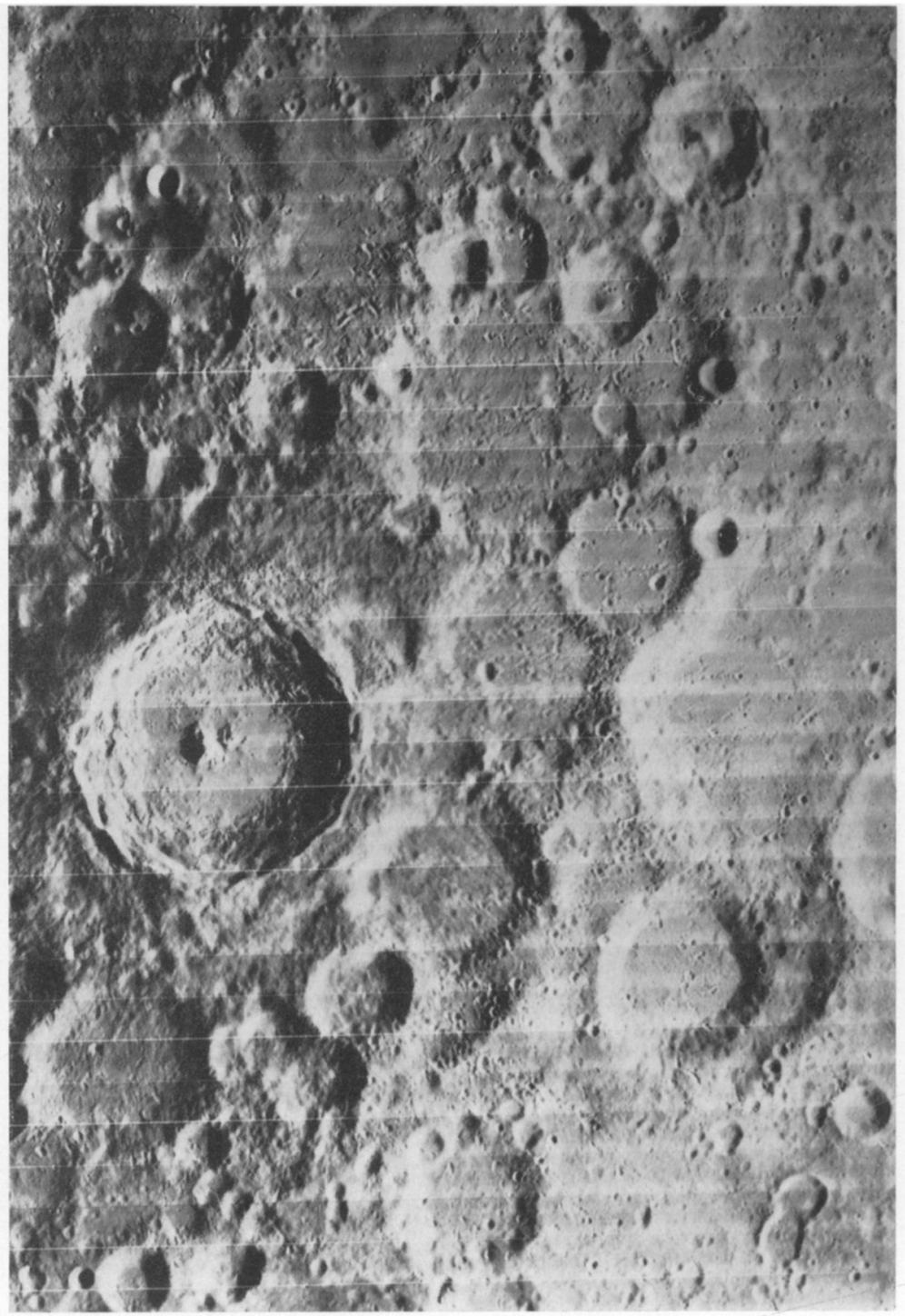

FIG. 45. 


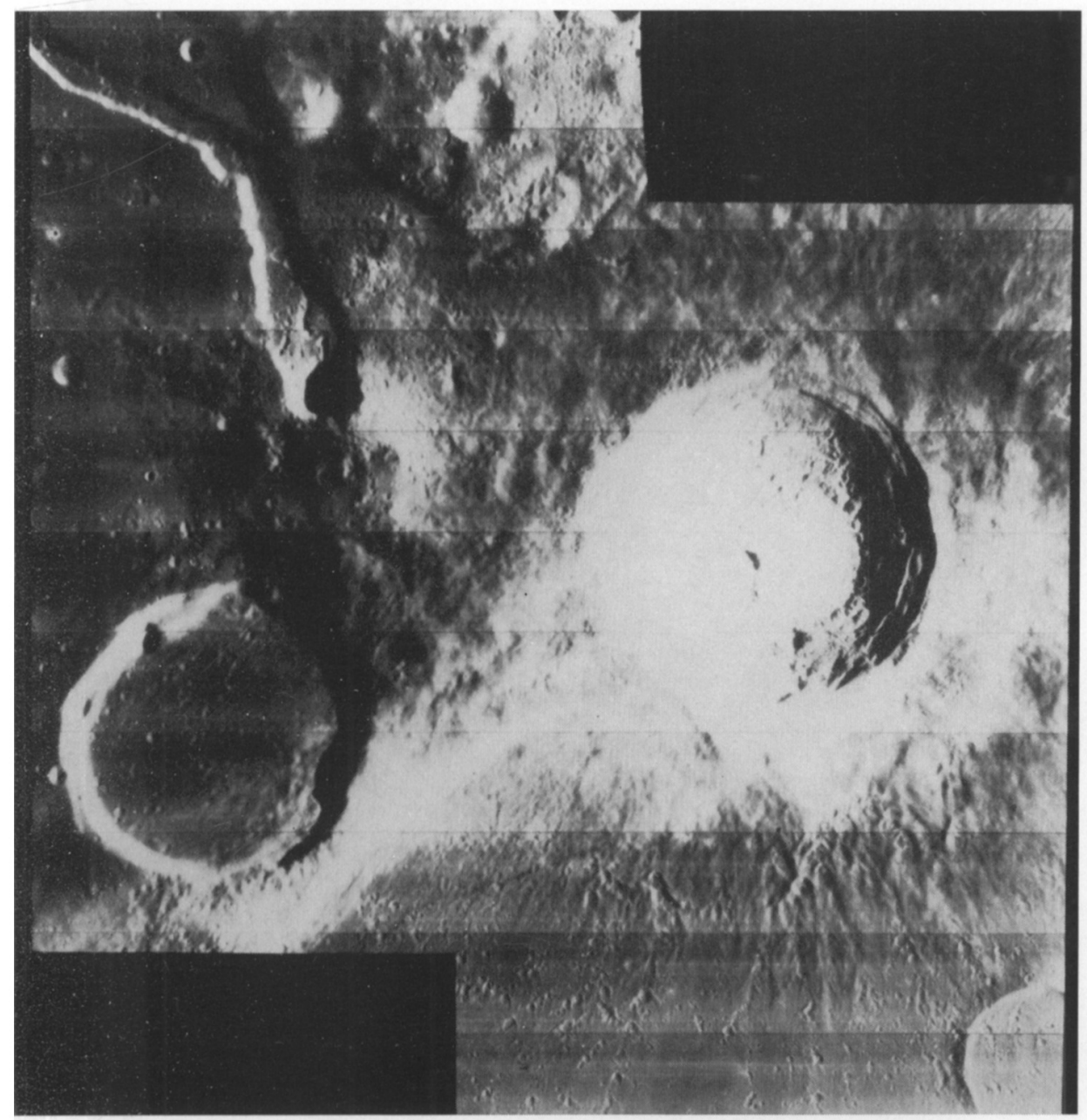

FIG. 46. 


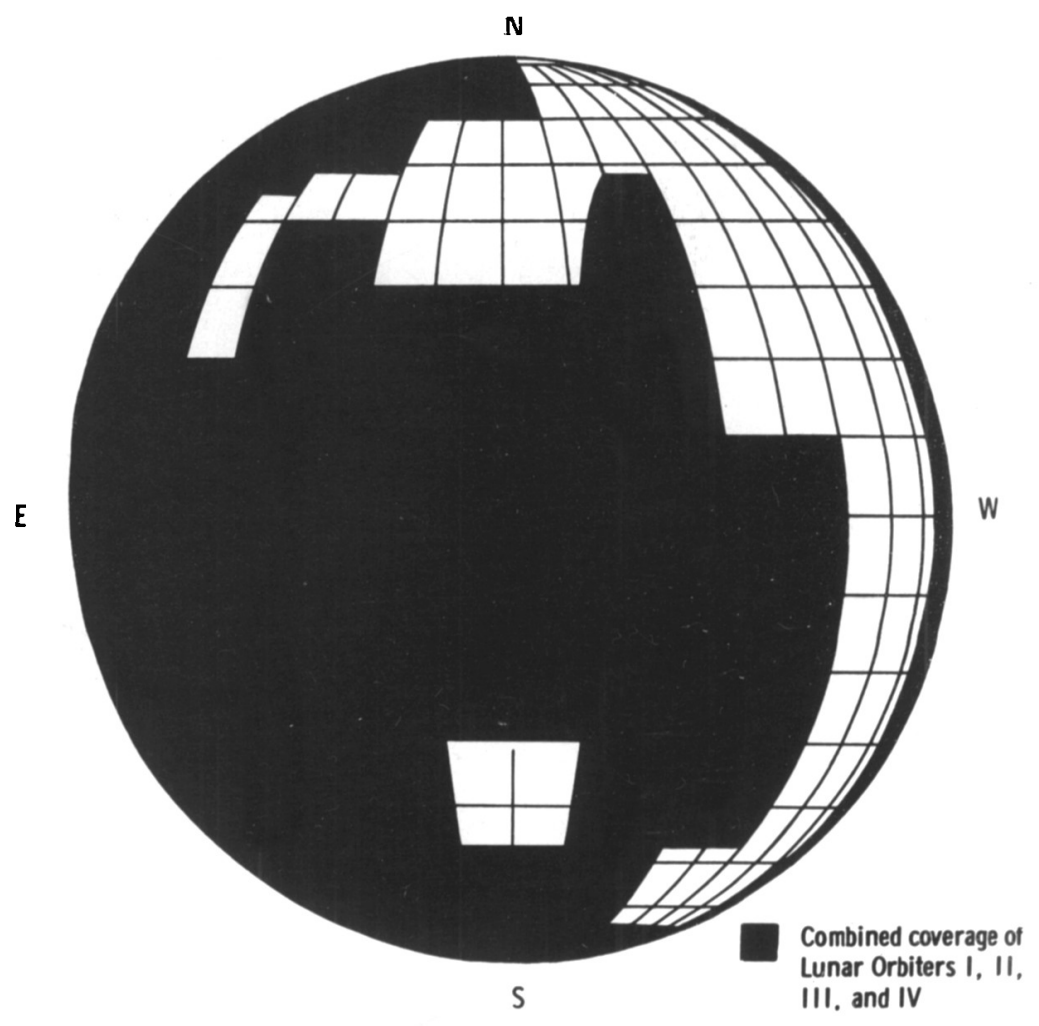

FIG. 47. 
PHOTOGRAPHIC RESULTS OF THE LUNAR ORBITER PROGRAM 519

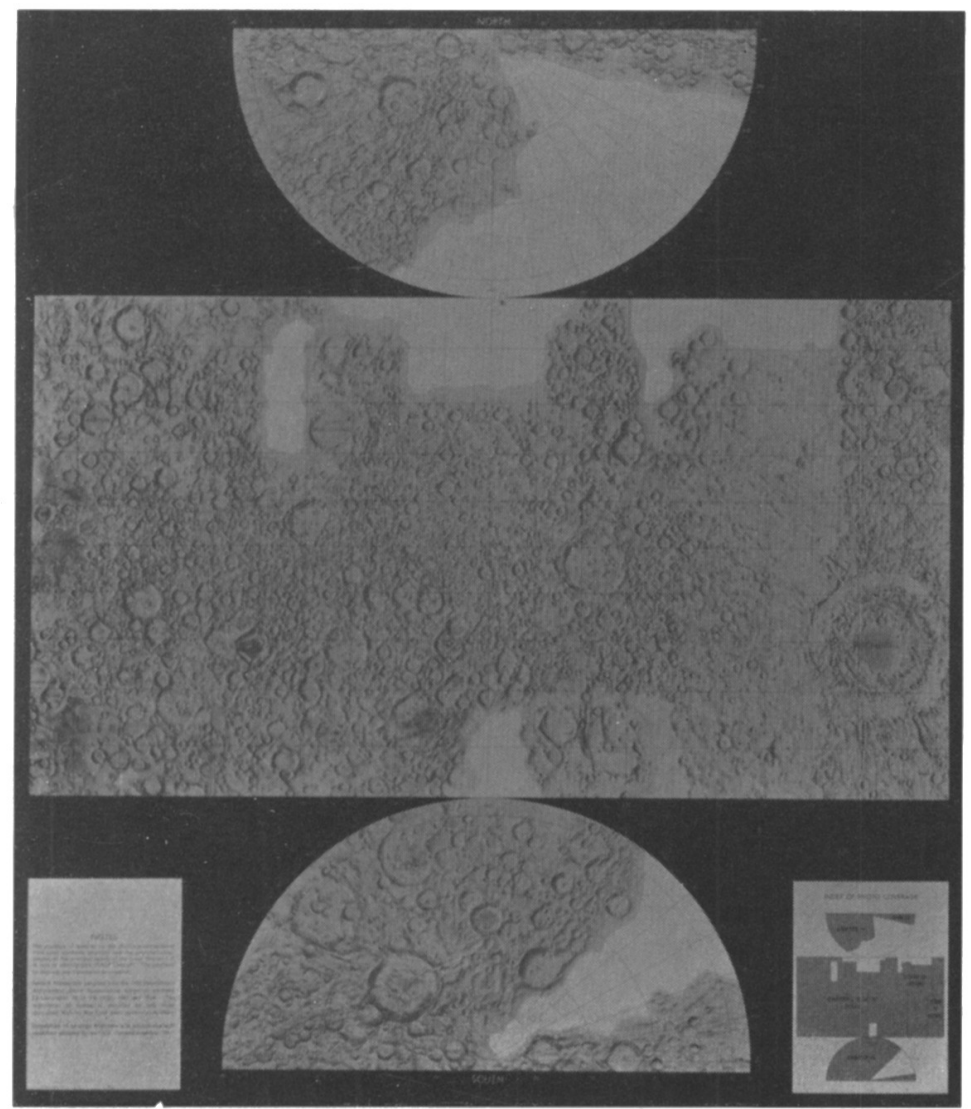

FIG. 48. 


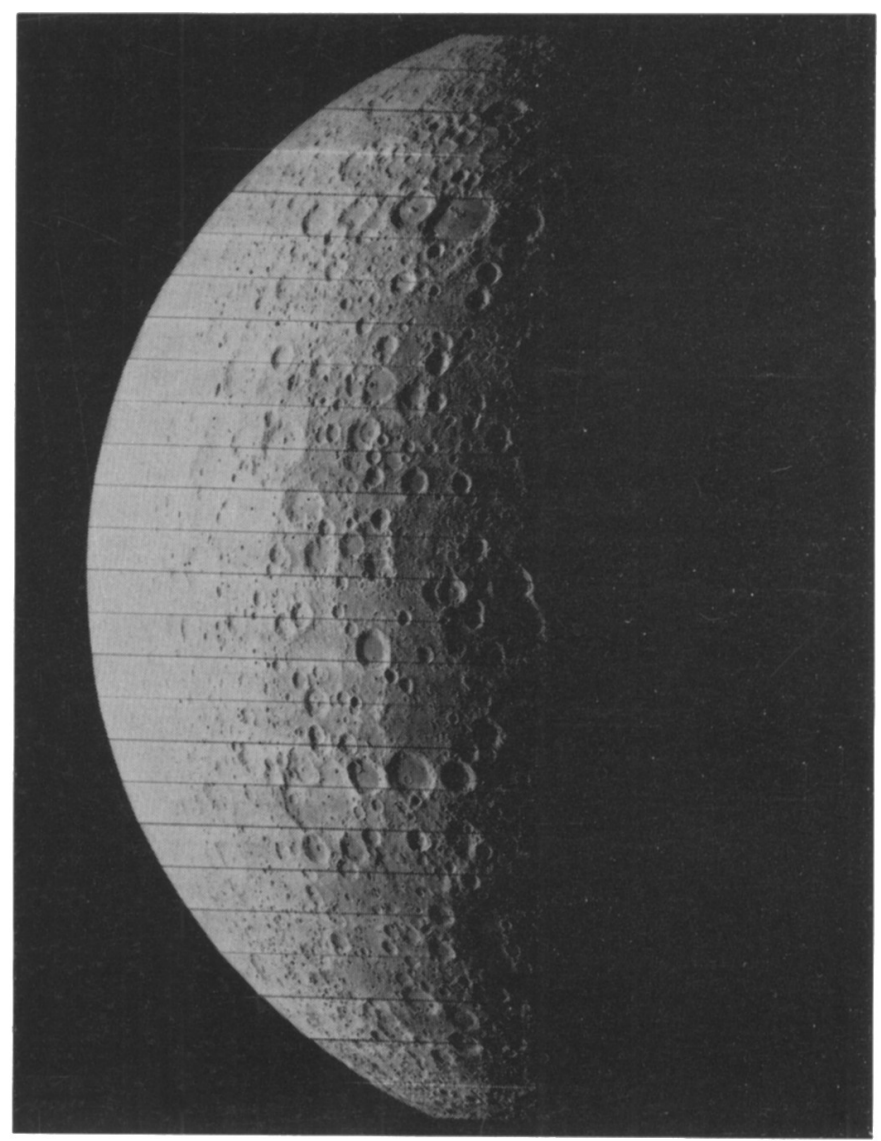

FIG. 49. 


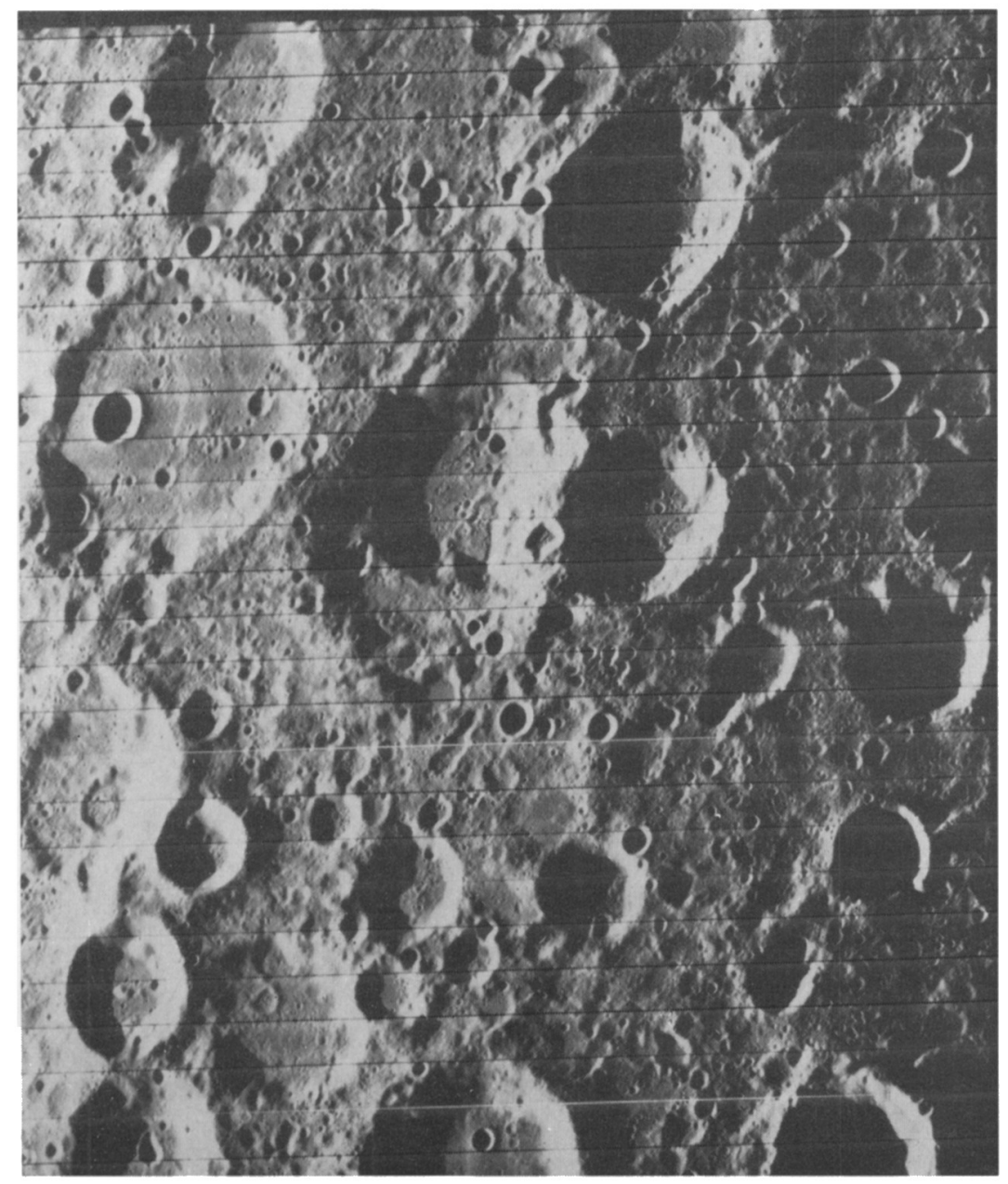

FIG. 50. 


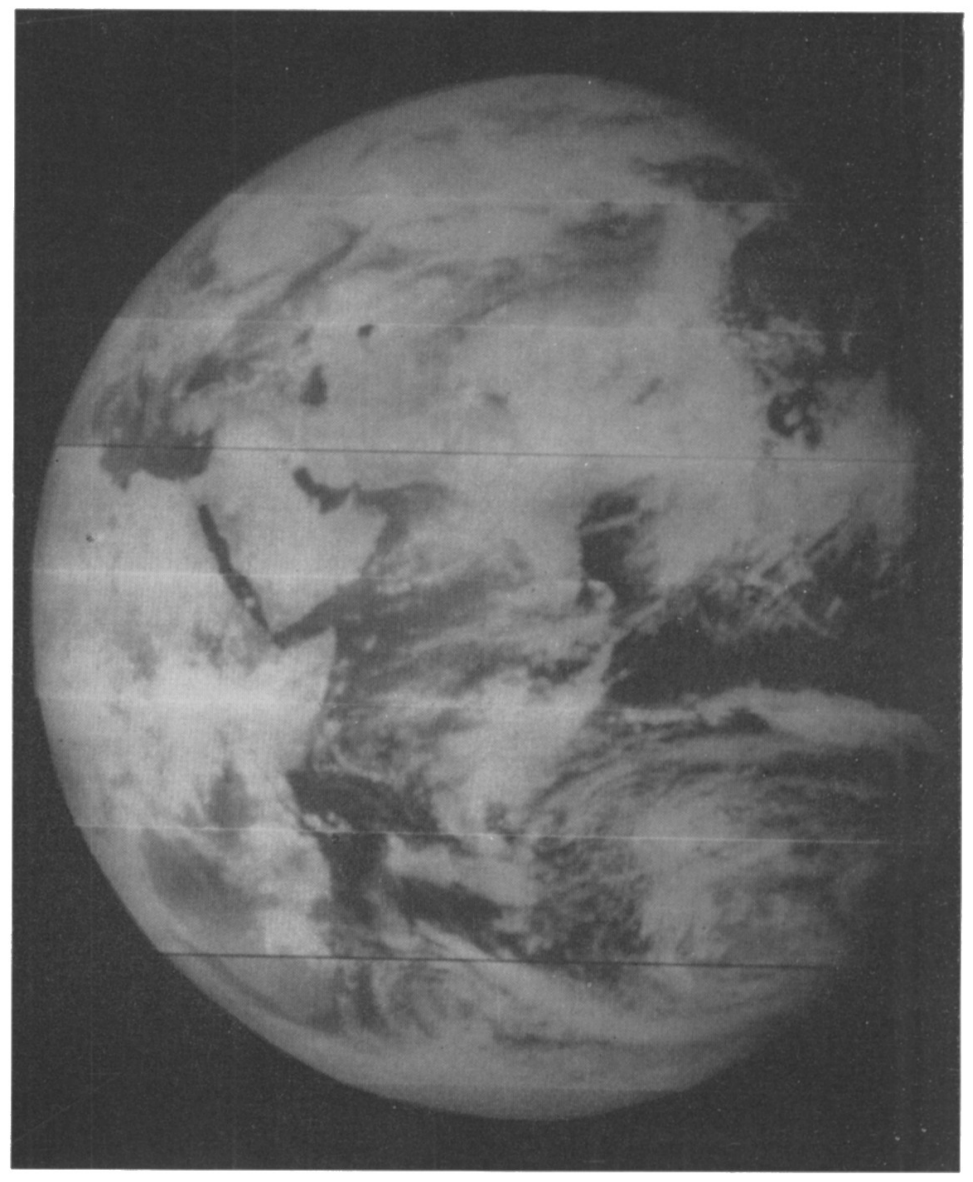

FIG. 51. 
photography. The absence of detail in this region was due to the lower resolution available from the Zond-III results.

Lunar Orbiter-V completed its photographic mission by the end of August 1967. One of its missions was to complete the photographic coverage of the far side. One of the first moderate-resolution frames of the far side from that mission is shown in Figure 49. Figure 50 shows $\frac{1}{3}$ of the high-resolution photograph taken at the same time. The last figure, Figure 51, does not show the Moon at all. It is a section of a high-resolution photograph of the Earth taken by Lunar Orbiter-V on August 8, 1967. Clearly seen between the scattered clouds are the outlines of the Mediterranean and Red Sea, the east coast of Africa and the Indian Peninsula.

The photographs presented in this paper have been limited to a small selection of the total number that have been obtained. There is sufficient photographic material available from the Lunar Orbiter program to provide lunar specialists with research material for a long time into the future. 